
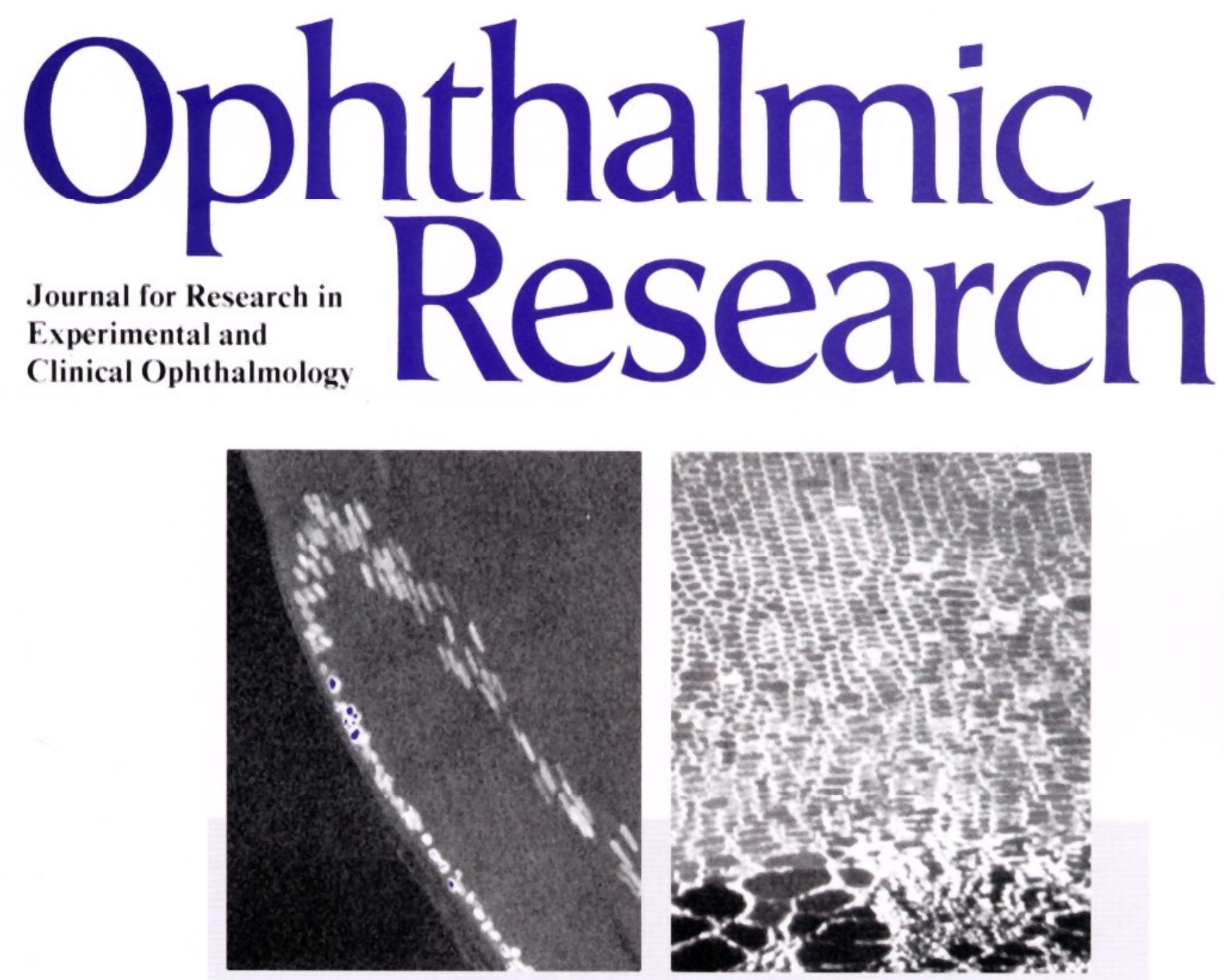

\title{
Development and Repair of Cataract Induced by
} Ultraviolet Radiation

Ralph Michael, Stockholm, Sweden

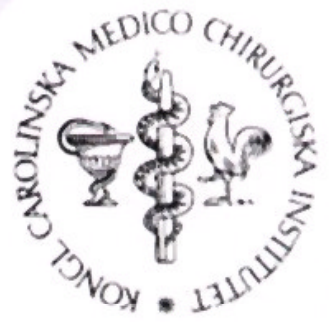


Ophthalmic

Research

\section{Development and Repair of Cataract Induced by Ultraviolet Radiation}

Ralph Michael, Stockholm, Sweden

St. Erik's Eye Hospital

Fleminggatan 22

S-11282 Stockholm (Sweden)

KARGER $\begin{aligned} & \text { Basel } \cdot \text { Freiburg } \cdot \text { Paris } \cdot \text { London } \cdot \text { New York } \cdot \\ & \text { New Delhi } \cdot \text { Bangkok } \cdot \text { Singapore } \cdot \text { Tokyo } \cdot \text { Sydney }\end{aligned}$ 


\section{ABSTRACT}

\section{Development and repair of cataract induced by ultraviolet radiation}

\section{Background.}

Several epidemiological investigations show a correlation between cataract development and the dose of ultraviolet radiation (UVR) received. It is experimentally well established that exposure of animal eyes to UVR induces cataract. Most cataracts develop as a gradual increase in lens opacity. D espite this, current estimations of toxicity for cataract are based on the concept that cataract is a binary event. Moreover, current exposure limits for UVR are based on subjective inspections with slit lamp microscopy.

\section{Purpose.}

The first purpose of the present study was to determine a statistically defined maximum acceptable dose for ultraviolet radiation-induced cataract based on quantitative data of forward light scattering in lenses. The second purpose was to find possible explanations for light scattering by investigating the morphology and the refractive index distribution in the lens. The third purpose was to describe the development of cataract after UVR on the cellular level.

\section{Methods.}

Six-week-old, female Sprague-D awley rats received UVR unilaterally in vivo. The radiation from a high pressure mercury lamp was collimated, passed through a water filter and an interference filter or a monochromator $\left(\lambda_{\mathrm{MAX}}=300 \mathrm{~nm}\right)$, and projected onto the cornea. The exposure time was $15 \mathrm{~min}$. The exposure dose ranged between 0.1 and $20 \mathrm{~kJ} / \mathrm{m}^{2}$ and the animals were kept between 6 hours and 32 weeks after exposure. The extracted lenses were photographed and forward light scattering was measured. Other methods included light microscopy, fluorescence microscopy, transmission and scanning electron microscopy, freeze-fracture and microradiography.

\section{Results and Conclusions.}

From a long-term experiment, it was concluded that UVR-exposed lenses scatter light more than their contralaterals and that a higher dose induces more light scattering. After exposure to $5 \mathrm{~kJ} / \mathrm{m}^{2}$, the mean forward light scattering remains unchanged between 1 and 32 weeks. Earlier observations, taken together with the current findings, indicate that the optimal time to detect low dose UVR-induced cataract is one week after exposure in rats. The intensity of forward light scattering increases exponentially with increased UVR dose between 0.1 and $14 \mathrm{~kJ} / \mathrm{m}^{2}$.

Based on this continuous dose-response, a method to determine a maximum acceptable dose to avoid UVR-induced cataract was developed. The statistically defined lower limit of pathologic light scattering is projected on the dose-response function. The dose corresponding to that point can be estimated and was suggested to be called the Maximum Acceptable D ose (MAD).

Two low dose UVR exposures with 0 or $6 \mathrm{~h}$ intervals between the exposures produce the same degree of lens opacification. When the second exposure follows 24 or $48 \mathrm{~h}$ after the termination of the first, lenticular damage increases. Repair processes between 24 and $48 \mathrm{~h}$ after exposure appear to be sensitive to UVR, and an additional exposure during this time may aggravate cataract development. 
Lenses exposed to UVR grow more slowly than their non-exposed contralaterals. This decrease in lens growth was more pronounced with increasing dose. Low doses led to decreased water content in the lens whereas high doses led to swelling. At 6 months after low dose UVR exposure, no global change of the refractive index was found. However, local variations of the refractive index induce a subtle cortical light scattering.

In vivo low dose UVR induces programmed cell death which peaks $24 \mathrm{~h}$ post-exposure and involves the entire lens epithelium. D ead cells are removed from the epithelium by phagocytosis. This leads to disintegration of the lens epithelium, associated with flake-like opacities at the lens surface. After one week, the epithelium and the equatorial parts of superficial lens fibers contain extracellular spaces. The extracellular spaces together with locally disarranged fibers produce a corrugated opaque lens surface and equatorial opacities.

Within several weeks after exposure, the lens epithelium recovers, and new fibers develop normally. The lens fibers regain normal osmotic properties and fill up the extracellular spaces. Repair, however, is incomplete, and disarranged fibers remain in the cortex, producing a subtle shell-shaped opacity. In this way, subtle damage to the lens fibers induced by UVR may accumulate during a lifetime and contribute to the formation of cortical cataract.

\section{Key words.}

ultraviolet radiation, cataract, forward light scattering, lens ultrastructure, refractive index, doseresponse, repeated exposure, apoptosis, in vivo, rat

ISBN : 3-8055-7044-9

Michael R: Development and repair of cataract induced by ultraviolet radiation. Ophthalmic Res. 2000; 32 - S1: 1-44.

\section{Address.}

Ralph Michael

St. Eriks Eye Hospital

Polhemsgatan 50

S - 11282 Stockholm

SWEDEN

ralph.michael@ altavista.net 


\section{LIST OF PAPERS}

This thesis is based on the following papers, referred to in the text by their Roman numerals:

I Michael R, Söderberg PG, Chen E.

$\mathrm{L}$ ong-term development of lens opacities after ex posure to ultraviolet radiation at $300 \mathrm{~nm}$.

O phthalmic Res.1996;28:209-218.

II Michael R, Söderberg PG, Chen E.

D ose response function for lens forward light scattering after in vivo ex posure to ultraviolet radiation.

Graefes Arch. Clin. Exp. Ophthalmol. 1998;236:625-29.

III Söderberg PG, Michael R, Merriam JC,

Maximum acceptable dose of ultraviolet radiation: A safety limit for cataract.

Manuscript.

IV Michael R, Löfgren S, Söderberg PG.

L ens opacities after repeated ex posure to ultraviolet radiation.

Acta Ophthalmol. 1999;77:690-693.

V Michael R, Vrensen G, van Marle J, G an L, Söderberg PG.

A poptosis in the rat lens after in vivo threshold dose ultraviolet irradiation.

Invest. Ophthalmol. Vis. Sci. 1998;39:2681-2687.

VI Michael R, Vrensen G, van Marle J, Löfgren S, Söderberg PG .

Repair in the rat lens after threshold ultraviolet radiation injury.

Invest. O phthalmol. Vis. Sci. 2000;41:204-212

VII Michael R, Brismar $\mathrm{H}$.

L ens growth and protein density in the rat lens after in vivo ex posure to ultraviolet radiation.

Manuscript. 


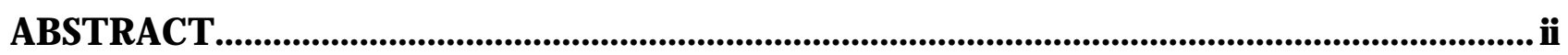

LIST OF PAPERS ................................................................................................................ iv

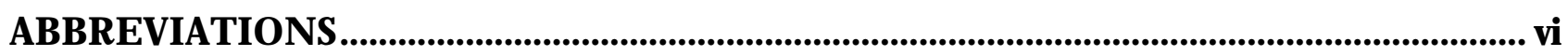

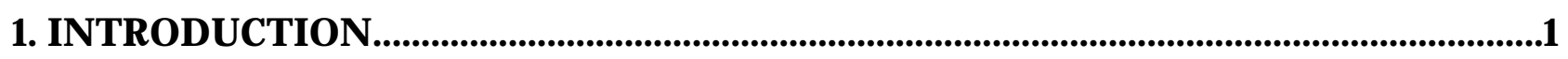

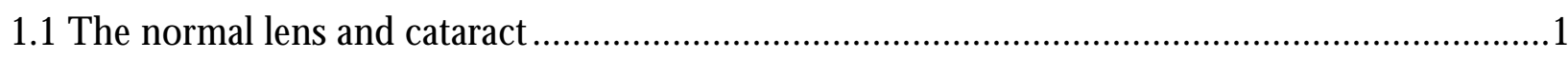

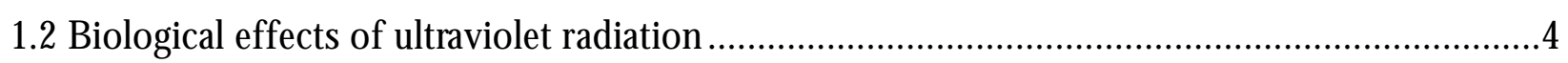

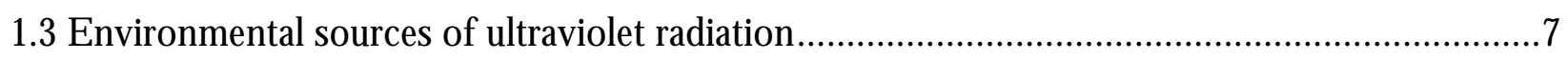

1.40 cular sunlight exposure and corneal transmission ........................................................10

1.5 Earlier research on ultraviolet radiation and cataract.........................................................12

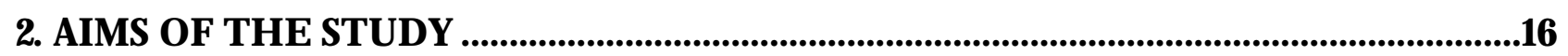

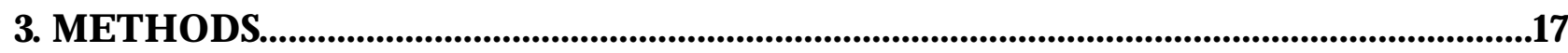

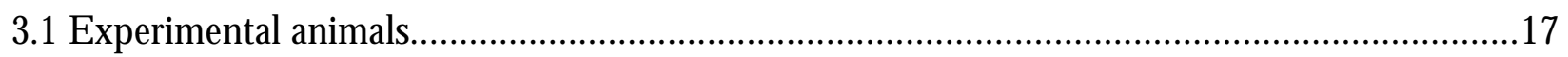

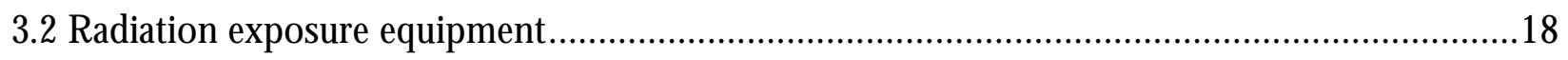

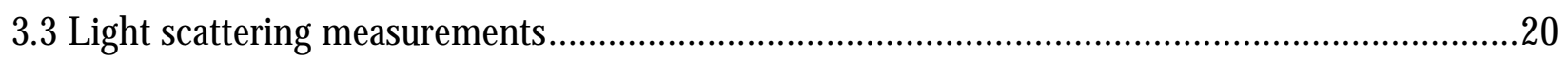

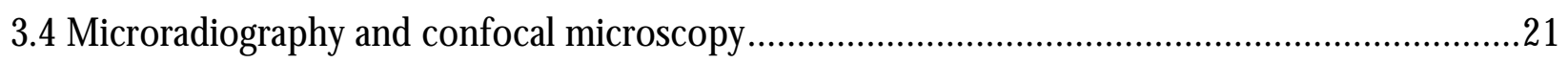

4. RESULTS AND DISCUSSION …………...........................................................................................23

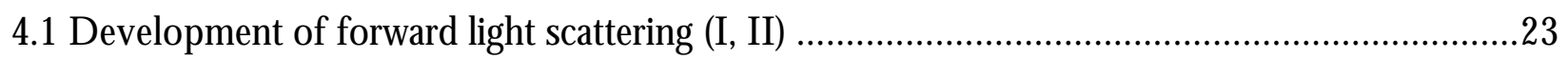

4.2 Estimation of a Maximum Acceptable D ose (III) ..............................................................26

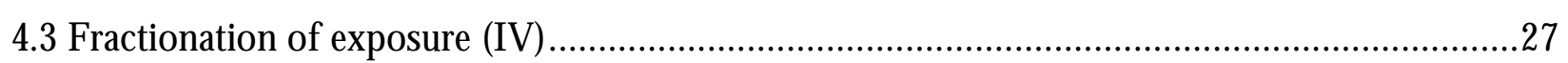

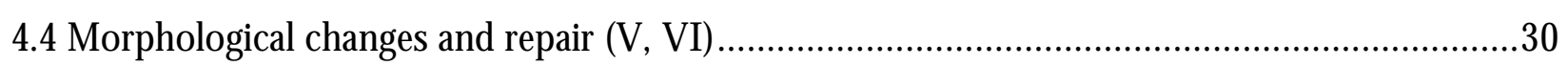

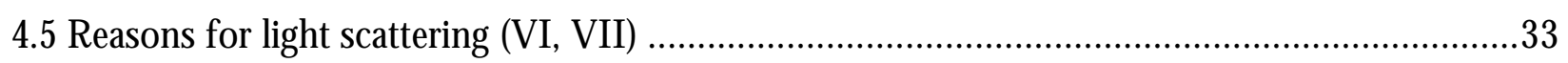

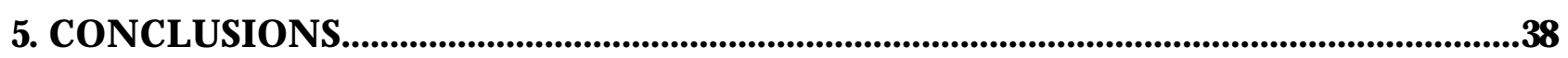

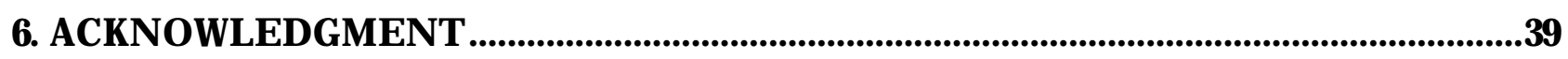

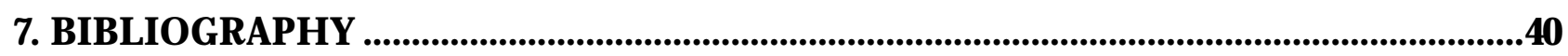

8. APPEN DIX

PAPER I - VII 


\section{ABBREVIATIONS}

ACGIH American Conference for Governmental and Industrial Hygienists

CIE Commission Internationale de l'E clairage (International Lighting Commission)

DNA Deoxyribonucleic acid

$\mathrm{kJ} / \mathrm{m}^{2} \quad$ Physical unit for the exposure dose $\left(1 \mathrm{~kJ} / \mathrm{m}^{2}=0.1 \mathrm{~J} / \mathrm{cm}^{2}\right)$

SEM Scanning electron microscopy

TEM Transmission electron microscopy

t ED C transformed E quivalent Diazemuls Concentration

TUNEL Terminal deoxynucleotidyl transferase (TdT) - deoxyuridine triphosphate (dUTP) nick end labeling

UVR Ultraviolet radiation

UVR-A Ultraviolet radiation between 315 and $400 \mathrm{~nm}$

UVR-B Ultraviolet radiation between 280 and $315 \mathrm{~nm}$

$\mathrm{W} / \mathrm{m}^{2} \quad$ Physical unit for the irradiance $\left(1 \mathrm{~W} / \mathrm{m}^{2}=100 \mu \mathrm{W} / \mathrm{cm}^{2}\right)$

WGA Wheat germ agglutinin (binds to cell-surface glycoproteins)

$\lambda \quad$ Physical symbol for wavelength 


\section{INTRODUCTION}

\subsection{The normal lens and cataract}

Some of the oldest cells of the human body are those found in the lens nucleus. Despite their longevity, the central cells in the lens remain transparent over an entire lifetime. "Opacification of the aged lens results from the accumulation of insults to the lens from many different stresses incurred over the lifetime of an individual" (Jose 1978). For optimal vision, all lens fiber cells developing after birth must remain transparent until old age, because there is no cell turnover in the lens cortex and nucleus (Clark 1994).

\subsubsection{Structure of the normal lens}

Anton van Leeuwenhoek (1638-1723), a Dutch microscopist who was the first to observe bacteria and protozoa, was also the first to describe the fine structure of he lens (Merriam 1996). In 1674, he wrote that the bovine lens was made up of "orbicular scaly parts, lying upon one another, which had their beginning out of the center" (van Leeuwenhoek 1939). He discovered that the lens consists of lens fibers which are arranged in rows and form layers.

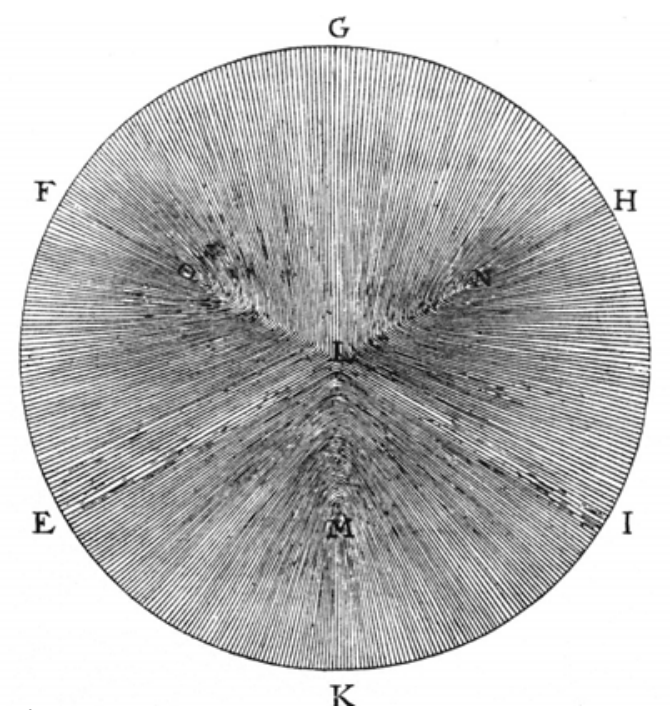

Figure 1 .

$\mathrm{L}$ ens of a $\mathrm{w}^{\prime}$ s eye. F ront view. D rawn by van $\mathrm{L}$ eeuwenhoek in a letter 1684. (Reprinted, with permission, from van L eeuwenhoek (1952). Copyright by Swets \& Z eitlinger BV , A msterdam.)
Leeuwenhoek realized that there was a regular order to the fibers. He described also the start and endpoints of the fibers and how they form opposite Y-figures on either pole of the lens (Figure 1). He did not name the sutures, but he described and drew them in a letter in 1684 (van Leeuwenhoek 1952), and estimated the number of lens fiber layers and the number of fibers lying side by side along the lens equator.

Sir David Brewster (1781-1868), a Scottish physicist noted for his experimental work in optics and polarized light, described the lens fibers as a regular transparent lamina of uniform thickness (Brewster 1816) Eigure 2). He found that the fiber is flat in cross-section and not round as described by van Leeuwenhoek. Brewster already used an optical diffraction technique to estimate the fiber dimensions and found that the fiber thickness is at least five times less than its maximum breadth. Brewster discovered the lateral binding of the lens fibers by protrusions or "teeth".

Herman von Helmholtz (1821-1894), a German scientist and philosopher and the inventor of the ophthalmoscope, gave the first comprehensive summary on refraction and image formation in the eye (Handbook of Physiological Optics (1867)). This included also more detailed knowledge on the lens structure as for instance the hexagonal shape of the fiber cross-section.

Allvar Gullstrand (1862-1930) was appointed the first Professor of Ophthalmology at Uppsala University in 1894. He continued the work of Helmholtz and made major contributions to the theory of light refraction in the eye. This included a solution for calculating the refraction in the crystalline lens, whose refractive index varies from layer to layer. In 1911, Gullstrand received the Nobel Prize for his work on the dioptrics of the eye. Gullstrand introduced an eye model with a lens consisting of an inner nucleus with a high refractive index (1.406), which is surrounded by an area with a lower refractive index (1.385). This was a three-layer model with theoretical values for the refractive index. 
The detailed distribution of the refractive index in the human lens was first measured quantitatively about 20 years ago (Fagerholm et al. 1981, Philipson \& Fagerholm 1981). These studies showed a constant refractive index of about 1.41 in the lens center occupying about $70 \%$ of the central lens diameter. The refractive index decreased almost linearly from this central core towards the lens periphery with a subcapsular refractive index of 1.37 .

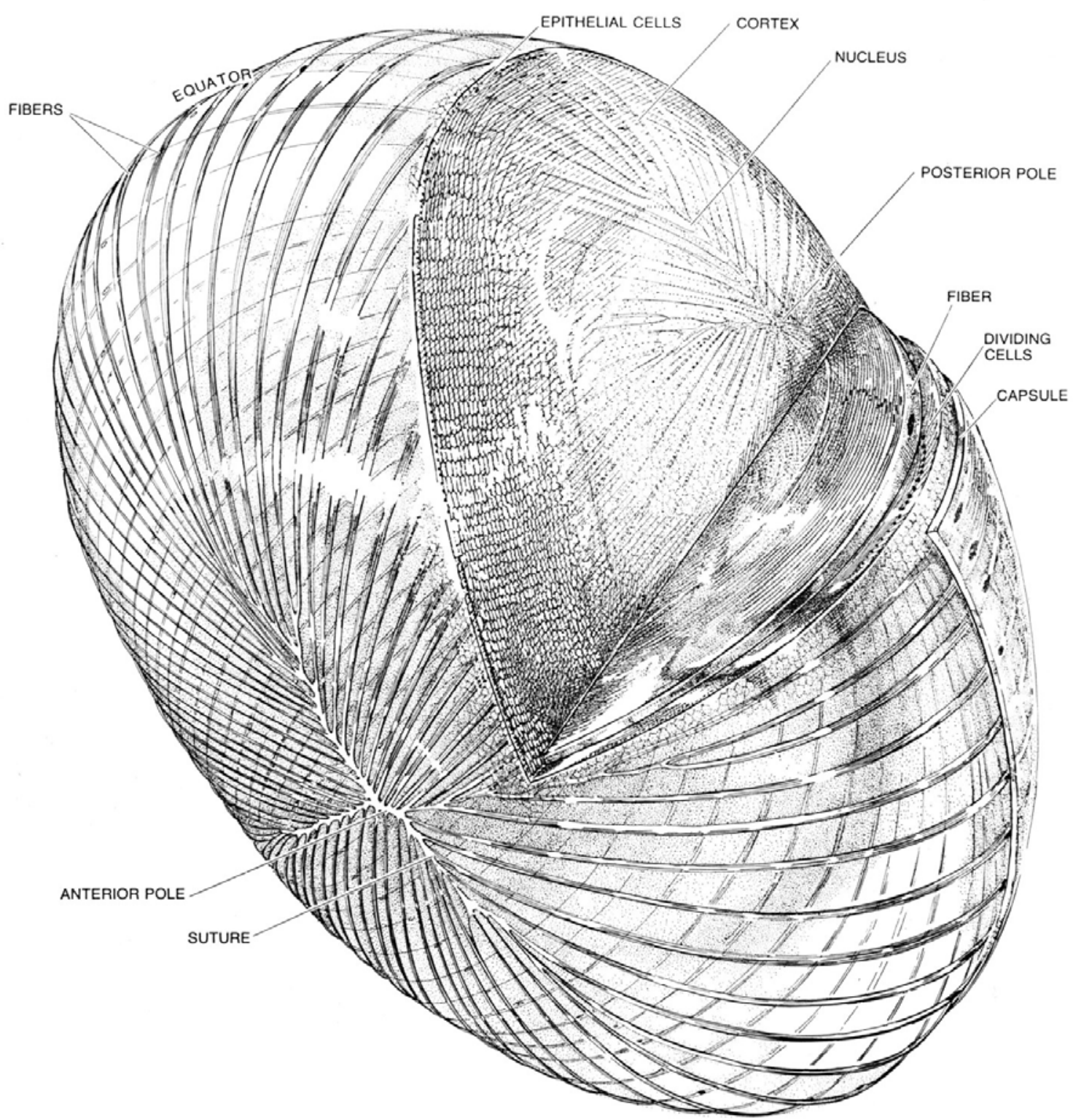

Figure 2.

Structure of the human lens.

(Reprinted, with permission, from van H eyningen (1975). C opyright by the artist C arol D onner, Renards Represents, N ew Y ork and Scientific A merican, $\mathrm{N}$ ew $\mathrm{Y}$ ork.) 


\subsubsection{Lens growth and cell division cycle}

Growth of the lens begins with the division of the epithelial cells in a circular band near the equator (Figure 2). The new cells elongate to form fibers that wrap around the periphery of the lens and meet at the sutures (van Heyningen 1975). All epithelial cells are capable of mitosis but mitotic activity is greatest in the peripheral region known as the germinative zone (Sallman 1952).

While epithelial cells maintain their replicative activity, prospective fiber cells stop DNA synthesis and mitosis. Lens fiber cell nuclei undergo pycnosis, degenerate and disappear (Modak 1972)(Figure 3). $\mathrm{G}$ ap junctions for water and ion transport develop in this fiber maturation process and the fibers lose their organelles at the same time.

Modak (1972) uses the cell division cycle to explain lens fiber differentiation (Figure 3).
The cell division cycle is the fundamental means of cell reproduction, to make a new individual from a single cell and to replace cells in the adult body. The standard cell cycle includes a cell division or mitosis phase (M), a DNA replication or synthesis phase (S), and two gap or growth phases $(\mathrm{G} 1, \mathrm{G} 2)$. The standard sequence of the cell cycle phases is: M - G1 - S - G2 - (Figure 3). From G1 phase, cells can enter a resting phase (G0) which can last days, weeks or years (Alberts 1994b). In the lens, epithelial cells in G1 phase can enter a terminal cell cycle with final mitosis and differentiation into fiber cells (Figure 3).

A large number of cells in a tissue are often synchronized with respect to cycle phase. The typical time for one cell cycle is about $24 \mathrm{~h}$, which was also found in neonatal rat lenses (Zelenka et al. 1997). However, the length of the cell cycle may be different for different developmental stages of the lens.

\section{TERMINAL LENS FIBER CELL DIFFERENTIATION.}

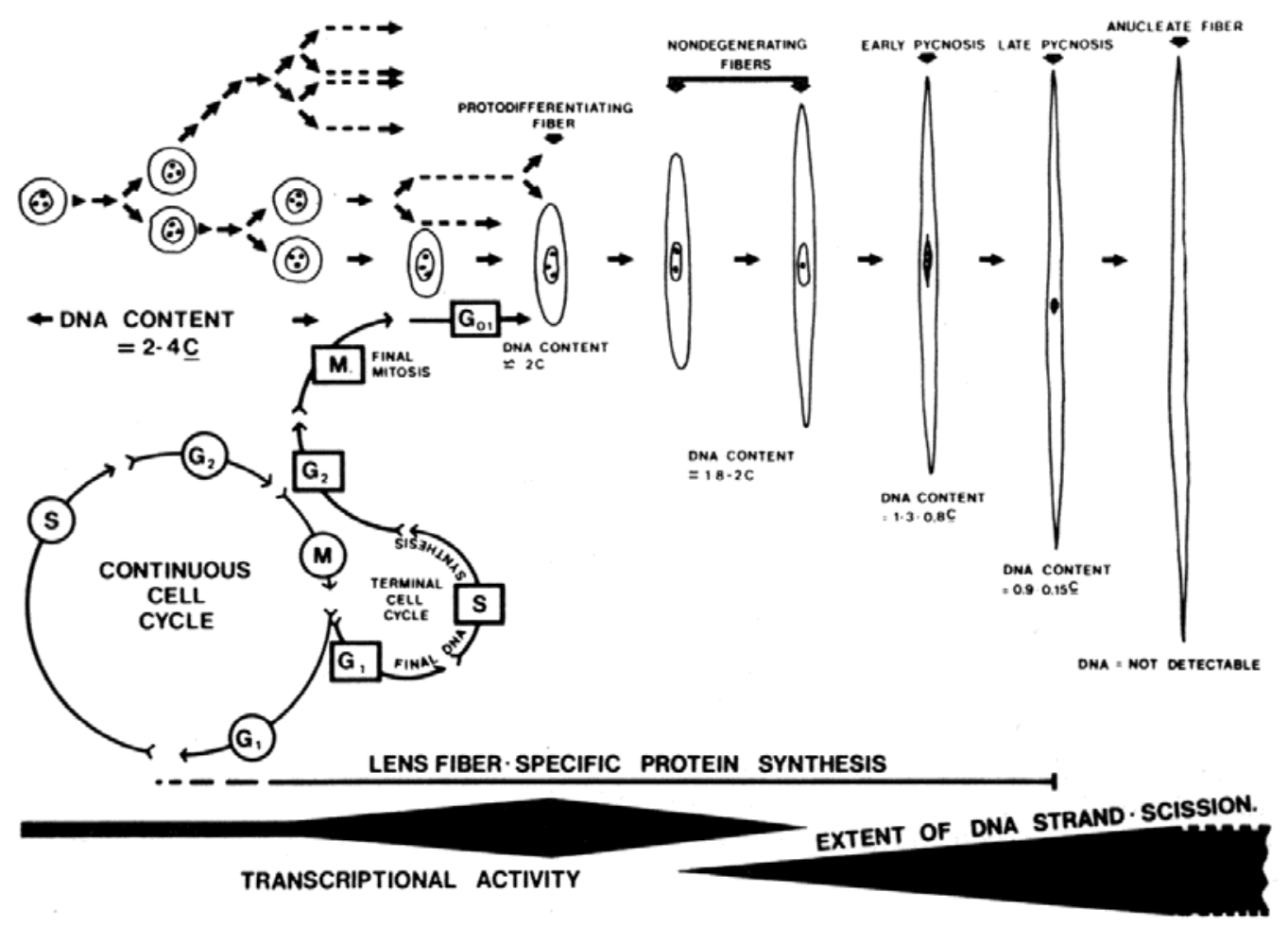

Figure 3.

Terminal lens fiber cell differentiation. (Reprinted, with permission, from Modak (1972). C opyright by M unk sgaard International Publishers, C openhagen.) 


\subsubsection{Lens transparency and cataract}

Cataract is the clinical term for reduced visual function due to optical disturbances in the crystalline lens. The word itself is of Greek origin and means downrushing or waterfall, and its use in this context probably refers to the unclear view from behind a waterfall. Cataract is one of the most common diseases that reduce visual acuity in elderly people. The prevalence of cataract approximately doubles with each decade after the age of 30 . In Gothenburg, the annual number of cataract operations is about 30 per 10000 inhabitants (Carlsson \& Sjostrand 1996). In Sweden, the cost of a cataract operation including the intra ocular lens is about 750 Euro.

The transparency of the crystalline lens is dependent on the regular organization of its cells and proteins. There are two main types of potential scattering centers in the lens: proteins in the fiber cytoplasm and membrane enclosed compartments. Fluctuations in the protein density induce small particle scattering whereas membrane enclosed compartments give rise to large particle scattering. The order and regularity of the lens fiber lattice also modulates total light scattering. High orderliness of the lattice results in destructive interference of the locally scattered light and hence less total light scattering.

\subsection{Biological effects of ultraviolet radiation}

Optical radiation between 290 and $2000 \mathrm{~nm}$ is an important environmental factor for many animals, including man. Humans receive more than $70 \%$ of their information from the environment through optical stimuli. Furthermore, light has an influence on a variety of physiological and psychological responses in the human body, such as e.g. the synchronization of biological rhythms (Hyman 1990, Wurtman 1975). Another important systemic effect is the immunosuppressive potential of UVR, which lowers the resistance against tumors and infections (van der Leun 1996).

Ultraviolet radiation can induce cell damage (phototoxic response) or alter the immune system
Physically, light scattering is due to fluctuations in refractive index. Random fluctuations of the refractive index in the lens are caused by membrane degeneration, protein aggregation, density fluctuation, phase separation, and disorientation of the cytoskeletal elements (Bettelheim 1985).

Unaltered transparency requires proper protein synthesis and a maintained equilibrium of water content and of the chemical and other constituents of the lens. Agents and factors that disturb the equilibrium induce cataract. Such factors are metabolic diseases, certain drugs, different types of radiation, genetic factors, ocular inflammation and physical injury. Age also plays an important role in cataract formation, as do nutrition, genetic factors, and race. Therefore, cataract is seen as an age related multifactorial disease (McCarty \& Taylor 1996, Müller-Breitenkamp et al. 1992, Stevens \& Bergmanson 1989).

(photoallergenic response). It can act directly on molecules or via a sensitizer.

Because the skin and the eye are directly exposed to UVR from the environment, they are the principal targets. Solar radiation causes erythema, synthesis of melanin and vitamin D in the skin, and changes in cellular functions in the skin, and UVR influences tumor suppresser genes. Skin carcinoma and melanoma are related to UVR exposure (van der Leun 1996).

D rugs and other agents can cause photosensitization to UVR. Photosensibilization can be used beneficially in photodynamic therapy of psoriasis or herpes, but may also be a harmful pathophysiological mechanism. 


\subsubsection{Pathological effects on the eye}

According to the fundamental law of Grothus-D raper, only radiant energy that is absorbed by the tissue can cause a biological response. Since 1845, it has been known from experiments by Brücke (1845) that when the eye is exposed to UVR near to the visible wavelengths the radiation is absorbed mainly by the lens.

In 1883, De Chardonnet investigated the transmission of light through ocular tissue from humans and various animal species (D eChardonnet 1883). He found that the human lens absorbs all radiation below $375 \mathrm{~nm}$, and the human comea, all radiation below $300 \mathrm{~nm}$. Interestingly, he also found that in the bovine lens there was a significant change in lenticular transmission depending on age. Figure 4 presents the current knowledge on the attenuation of UVR on passage through the human ocular media.

The shortest UVR wavelength band of biological interest is UVR-C $(\lambda=180-280 \mathrm{~nm})$. The human receives UVR-C only from artificial sources. Because it is completely absorbed by the cornea (Figure 4), this radiation causes injury only of the comea (photokeratitis) and conjunctiva.

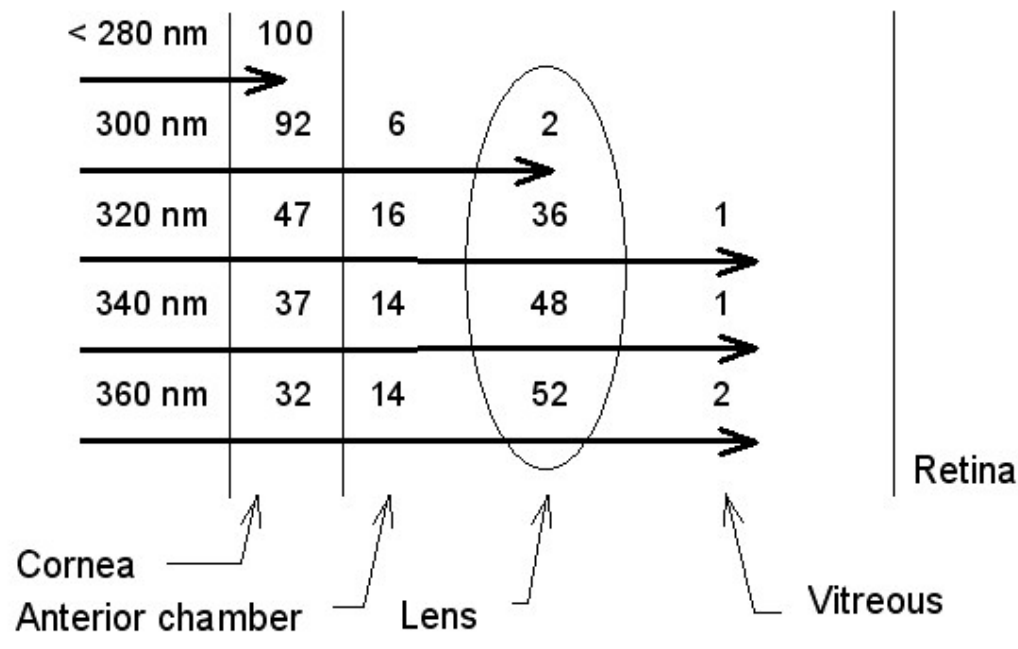

Somewhat longer wavelengths are called UVR-B $(\lambda=280-315 \mathrm{~nm})$. UVR-B is mainly absorbed by the cornea and contributes to photokeratitis. A small fraction, however, also reaches the lens. The absorption in the crystalline lens rises between 300 and $310 \mathrm{~nm}$ (Sliney \& Wolbarsht 1980a) and the lens absorbs all the UVR-B that passes the cornea (Förster \& Busse 1991). Therefore, this radiation can be especially harmful to the lens. The UVR band with the longest wavelengths and lowest energy is the UVR-A $(\lambda=315$ - $400 \mathrm{~nm})$. Like UVR-B, this radiation may contribute to cataract, albeit to a lesser extent, as less UVR-A is absorbed in the lens. UVRA with wavelengths between 340 and $360 \mathrm{~nm}$ or longer, passes through the lens and may reach the retina (Figure 4). This waveband and blue light are postulated to cause age related macular degeneration. Other ocular diseases related to UVR are pterygium (Dhir et al. 1967), a duplicate conjunctiva growth on the cornea, and pinguecula (Taylor et al. 1988), yellow hyalinic deposits close to the limbus.

\section{Figure 4.}

A ttenuation of ultraviolet radiation in the human eye for different wavelengths. $\mathrm{N}$ umbers are the percentages of incident radiation on the cornea absorbed by each tissue. (B oettner \& W olter 1962) 


\subsubsection{Mechanisms of lens damage}

There are multiple mechanisms through which UVR damages the lens and contributes to cataract formation.

The first lenticular target for UVR-B that passes the cornea is the epithelium $a>300 \mathrm{~nm}$ ), because the lens capsule does not absorb this radiation significantly (Söderberg et al. 1996). The epithelial cells are mitotic cells that divide in the germinative zone and differentiate into fiber cells (Figure 5). These fiber cells elongate and envelop the fibers that were formed earlier in life (Jose 1978). Damage to the epithelium caused by UVR-B will therefore be mediated to growing lens fibers (Hightower 1995, Jose 1986).

The most important UVR-absorbing component in the lens is tryptophan. Other amino acids (phenylalanine, tyrosine and cystine), as well as 3-hydroxykynurenine glycoside, contribute to the absorption of UVR in the lens (Sydenham 1995, Tuffs 1991).

\begin{abstract}
Absorbed UVR-photons excite lens molecules, creating free radicals which increase the oxidative stress on the lens (Figure 6). This induces damage to the DNA, proteins and lipids. UVR can induce single and double strand breaks in the DNA and can damage the bases of DNA by inducing e. $g$. pyrimidine dimers. This is affects lens cell differentiation and protein synthesis (Jose 1978). Lipid peroxidation and the inhibition of oxidative enzymes alters membrane functions and cell metabolism and finally leads to cellular edema (Kistler \& Bullivant 1989, Müller-Breitenkamp et al. 1992, Spector 1995). All these changes disturb the order and placement of the lens cells and lead to an increase of light scattering in the lens (Figure 6). There are different time scales for different types of UVR induced damage; cell misdifferentiation will take more time to induce light scattering as compared to changes that induce edema.
\end{abstract}

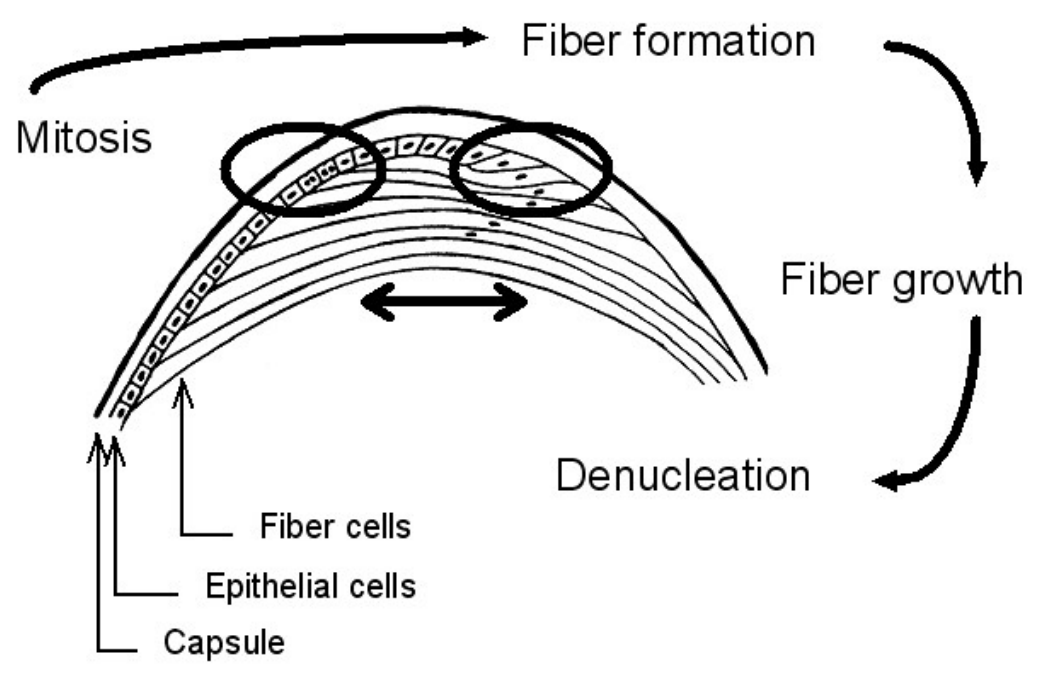

Figure 5.

Schematic drawing of lens fiber development. Diagram shows a sagittal section of the nuclear bow region. The anterior of the lens is left, the equator on top and posterior right. 


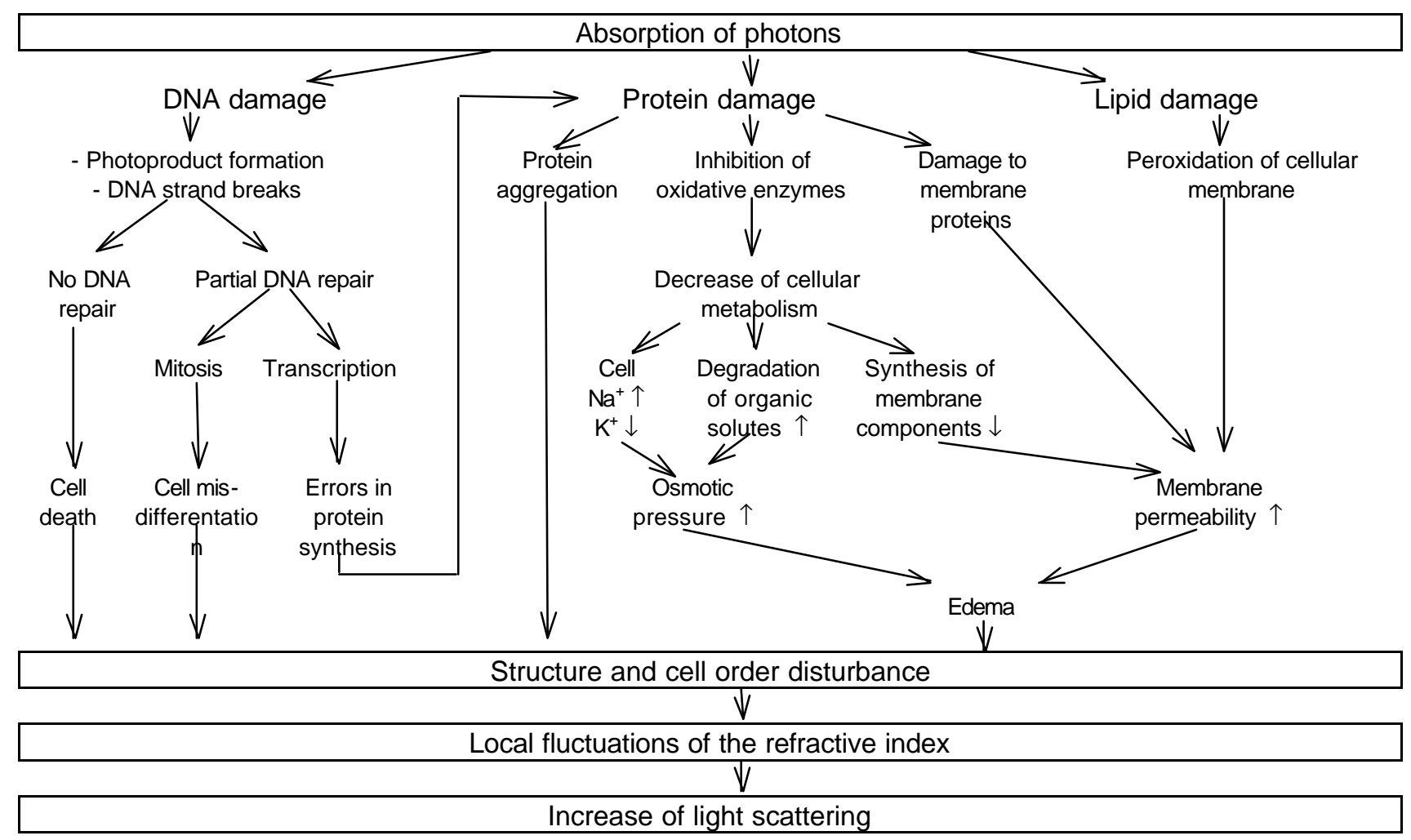

Figure 6.

Possible pathways for cellular damage in the lens induced by UV R. ( $\uparrow \ldots$ increase, $\downarrow$... decrease )

\subsection{Environmental sources of ultraviolet radiation}

More time for leisure and vacations, frequently spent in southern latitudes, coupled with a longer lifeexpectancy, has increased the amount of natural ultraviolet radiation exposure that people in Europe and North America receive in their lifetime (Johnson et al. 1976, Moan \& Dahlback 1992, Nolan \& Amanatidis 1995). This exposure is enhanced by atmospheric changes which allow a greater amount of shorter wavelength radiation to reach the earth's surface (D obson 1963, Munakata 1995, Zerefos et al. 1995). Artificial sources of UVR have found increasing use in sun tanning and industry, e.g., sterilization, photochemistry. All of these factors have increased our total environmental exposure to UVR.

\subsubsection{Terrestrial exposure}

Solar radiation approaching the earth's atmosphere must penetrate the atmosphere along a slanted path. The length of the path is determined by the solar elevation angle, which varies with time of day, season and latitude (Figure 7), and is often expressed as relative thickness of the atmosphere or air mass. The air mass is the ratio of the length of the slant path to the length of the vertical path (Gates 1966). The length of this path determines the attenuation of the solar radiation that occurs by atmospheric absorption and scattering mainly due to water and oxygen. Another factor influencing the path length of the solar rays is altitude. 


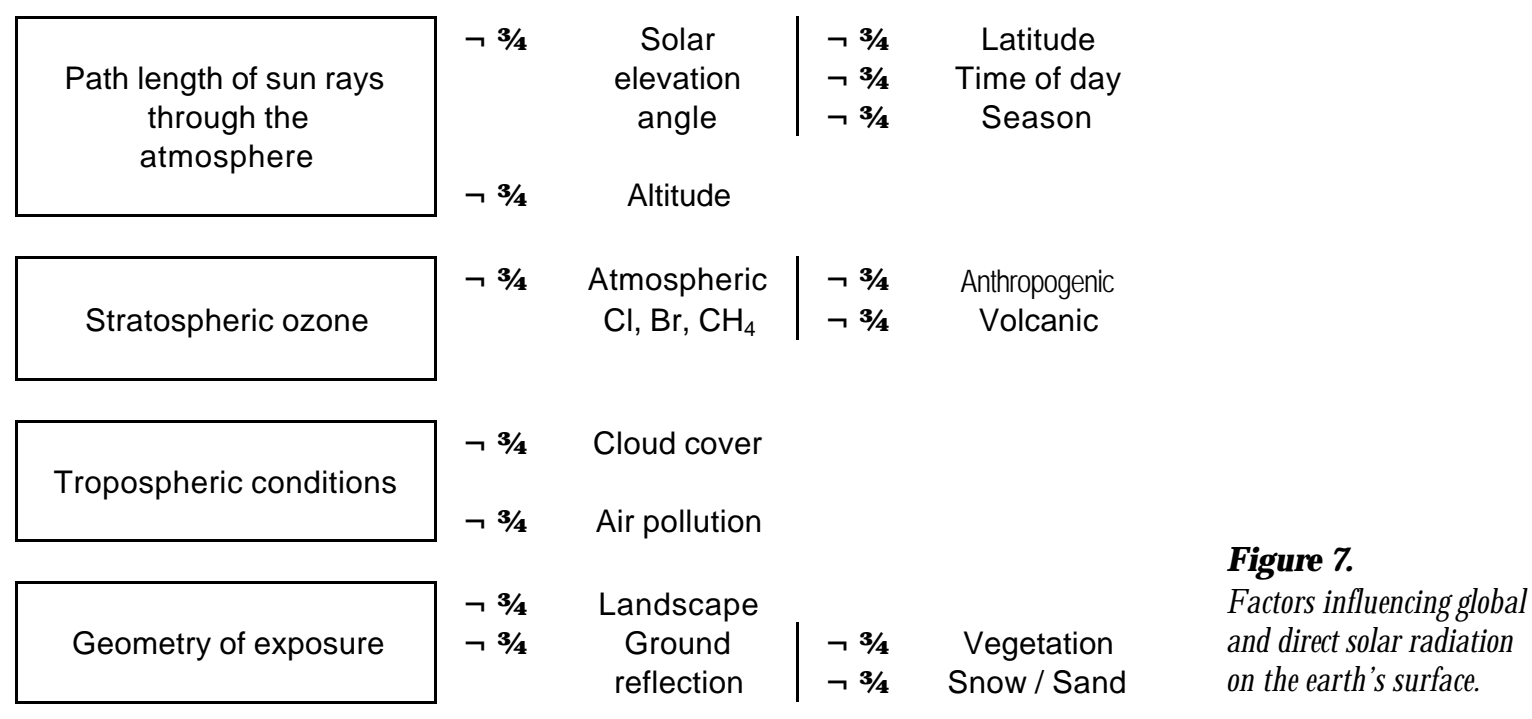

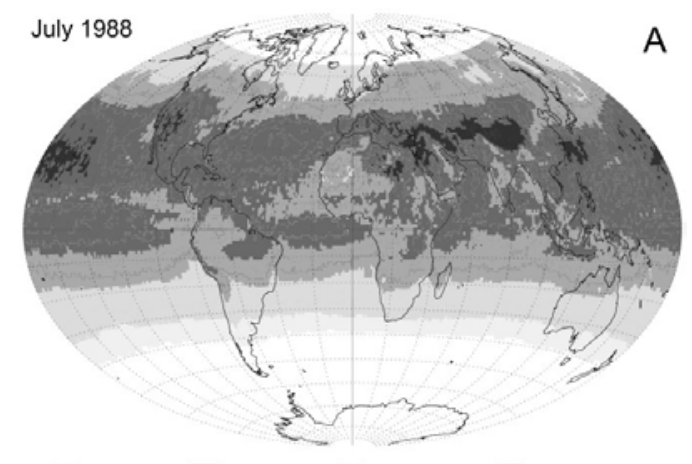

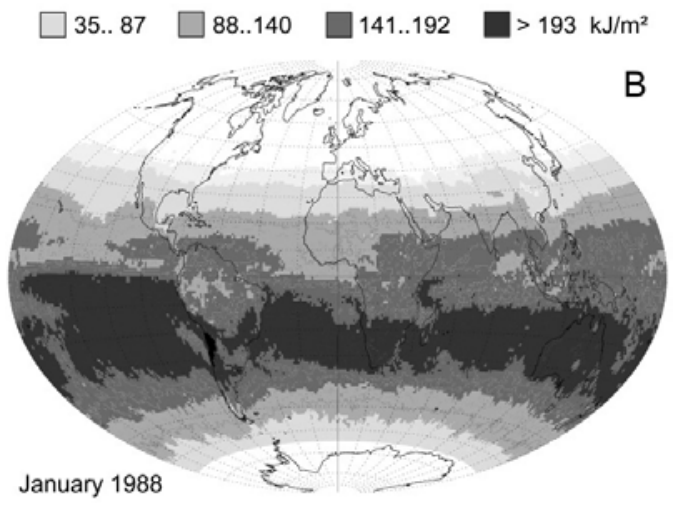

Figure 8.

The geographical distribution of monthly-integrated UV R from 290 to $400 \mathrm{~nm}$ weighted by the CIE erythemal action spectra.

(A dapted from $\mathrm{H}$ erman et al, J. G eophys. Res., V ol. 104 D 10, pp 12059-12076, 1999. Copyright by the A merican $\mathrm{G}$ eophysical U nion.)
Figure 8 illustrates the distribution of solar UVR at the earth's surface. It gives the solar radiation weighted by the CIE erythemal action spectrum (Figure 12) and integrated for 30 days. The data are estimated using the ozone amount, cloud transmittance, aerosol amounts, and surface reflectivity from the solar UVR backscattered from the earth's atmosphere as measured by TOMS (Total O zone Mapping Spectrometer), and independently measured values of the extraterrestrial solar radiance (Herman 1999).

July is the month with the maximum solar radiation for the Northern hemisphere (Figure 8a) and January for the Southern hemisphere (Figure 8b). The impact of latitude, altitude and vegetation on solar UVR is visible in Figure 8 There is always a North-South difference in the UVR dose. The region of Tibet and the Himalayas (Figure 8a) as well as the Andes in South America (Figure 8b) have high values of UVR due to high elevation. The Amazonas rain forest causes low values of UVR as compared with neighboring areas at the same latitude (Figure 8).

Figure 9 shows two sample spectra of the solar UVR spectrum at different latitudes. Both spectra were measured at the annual maximum solar elevation angle for each location (Wester 1987, 1996). The entire UVR spectrum is attenuated more in Stockholm than on the Canary Islands, and the most significant difference is found between 290 and $310 \mathrm{~nm}$. 


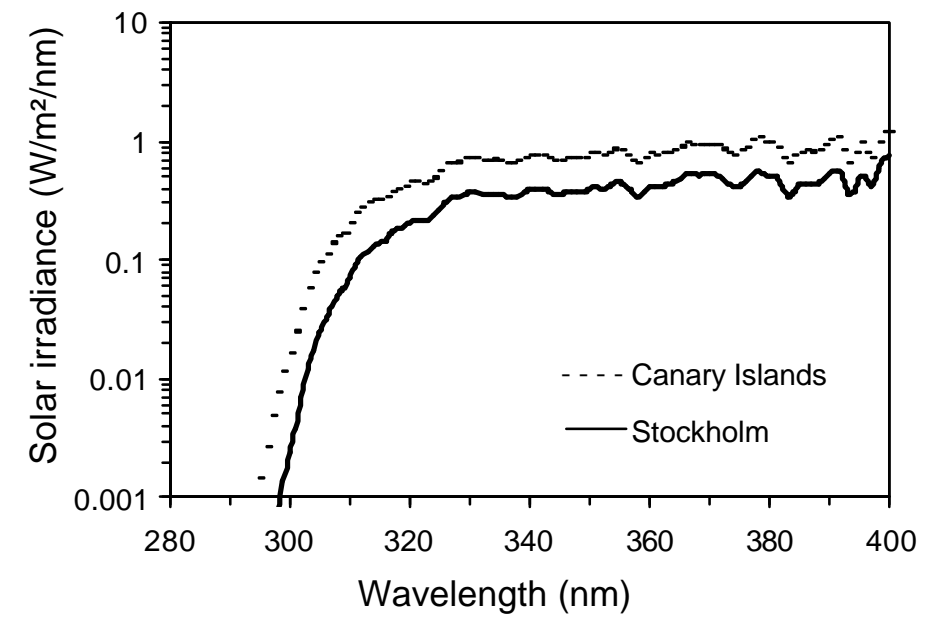

Figure 9.

Measured spectral solar irradiance on the earth's surface for different latitudes. Measurements taken under a clear sky at solar noon on L a Palma, Canary Islands, latitude $28^{\circ} \mathrm{N}$, altitude $2350 \mathrm{~m}$, solar elevation angle $85^{\circ}$ (air mass 1.0), 30.06.1986 and in Stockholm, Sweden, latitude $59.3^{\circ} \mathrm{N}$, altitude $0 \mathrm{~m}$, solar elevation angle $50^{\circ}$ (air mass 1.3), 07.07.1989 by W ester (1996).

$\left(1 \mathrm{~W} / \mathrm{m}^{2}=100 \mu \mathrm{W} / \mathrm{cm}^{2}\right)$

\begin{tabular}{|c|c|c|c|}
\hline & \multicolumn{2}{|c|}{ Total terrestrial solar irradiance $\left(\mathrm{W} / \mathrm{m}^{2}\right)$} & \multirow{2}{*}{$\begin{array}{c}\text { Safe ocular exposure time to } \\
\text { avoid cataract * } \\
\text { (min) }\end{array}$} \\
\hline & $\begin{array}{c}\text { UVR-B } \\
(280-315 \mathrm{~nm})\end{array}$ & $\begin{array}{c}\text { UVR-A } \\
(315-400 \mathrm{~nm})\end{array}$ & \\
\hline Canary Islands & 3.2 & 65.8 & 23 \\
\hline Stockholm & 0.9 & 34.8 & 65 \\
\hline
\end{tabular}

Table 1. M easured total solar irradiance on the earth's surface for different latitudes. F or environmental conditions see figure 9 . The safe ocular ex posure time is calculated according to Pitts (1993).

( ${ }^{*}$... for constant gazing against the sun.)

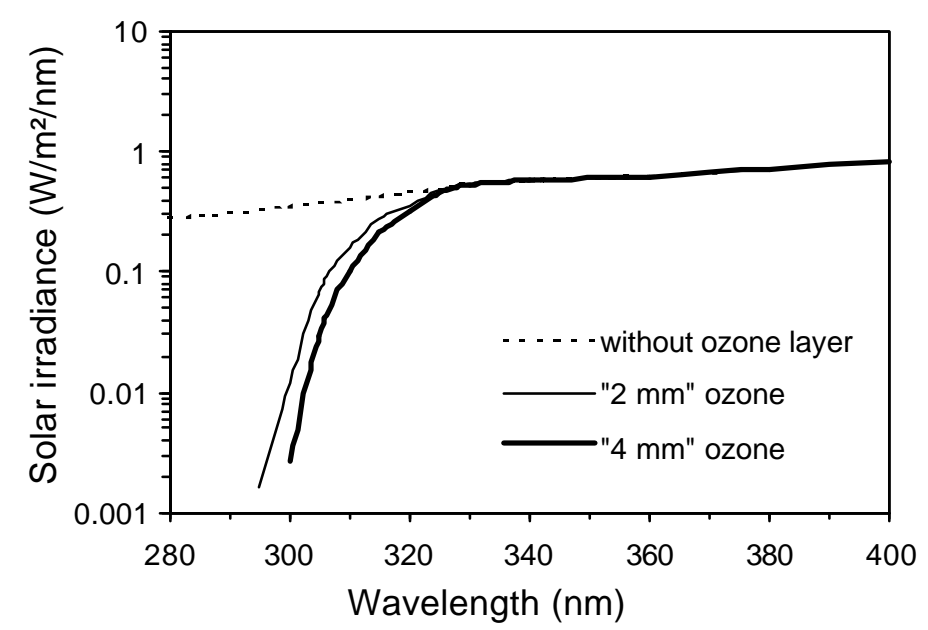

\section{Figure 10.}

Theoretical spectral solar irradianœ on the earth's surface for different stratospheric ozone concentrations. Calculated from relative data by D obson (1963) for dear sky, sea level and solar elevation angle $90^{\circ}$ using data from empirical equations by $\mathrm{D}$ iffey (1977) based upon the measurements of Bener (1972).

$\left(1 \mathrm{~W} / \mathrm{m}^{2}=100 \mu \mathrm{W} / \mathrm{cm}^{2}\right.$;

"1 mm" ozone = 100 D obson units)

\begin{tabular}{cccc}
\hline & \multicolumn{2}{c}{ Total terrestrial solar irradiance $\left(\mathrm{W} / \mathrm{m}^{2}\right)$} & $\begin{array}{c}\text { Safe ocular exposure time to } \\
\text { avoid cataract * } \\
\text { (min) }\end{array}$ \\
\cline { 2 - 4 } & $\begin{array}{c}\text { UVR-B } \\
(280-315 \mathrm{~nm})\end{array}$ & $\begin{array}{c}\text { UVR-A } \\
(315-400 \mathrm{~nm})\end{array}$ & 6 \\
without ozone & 12.4 & 55.2 & 30 \\
"2 mm" ozone & 2.6 & 54.6 & 48 \\
\hline "4 mm" ozone & 1.7 & 54.2 & 48 \\
\hline
\end{tabular}

Table 2. Theoretical total solar irradianœ on the earth's surface for different ozone concentrations. F or environmental conditions see figure 10. The safe ocular ex posure time is calculated according to Pitts (1993). - (*... for constant gazing against the sun.) 
Due to the absorption of short-wave solar radiation $(\lambda=140-200 \mathrm{~nm})$ by oxygen, ozone is formed in the stratosphere. The ozone in turn absorbs solar radiation with longer wavelengths $(\lambda=200$ $300 \mathrm{~nm}$ ) and is split into oxygen (Phillips 1983). In this way, the absorption of UVR by oxygen and ozone protects the earth's surface from all solar radiation shorter than $290-300 \mathrm{~nm}$. This stratospheric equilibrium may be upset by the catalytic disassembly of nitric oxides $\left(\mathrm{N}_{2} \mathrm{O} ; \mathrm{NO}\right)$ in the presence of volcanic or anthropogenic chlorine, bromine or methane (Figure 7). Figure 10 shows the protective effect of the ozone layer. The ozone molecules are spread throughout a layer which is several kilometers thick. The concentration of ozone, however, is commonly described as the thickness this layer would have were it compressed against the earth's surface. The monthly average in Sweden usually varies between 2.5 and $4.5 \mathrm{~mm}$ ozone during the year (Wester 1993). Different stratospheric ozone concentrations affect the solar spectrum only in the UVR-B region Figure 10 and Table 2) (D obson 1963). The effect is, again, most prominent around $300 \mathrm{~nm}$.

To illustrate the damaging potential of UVR, the time for safe constant viewing to the sun is calculated according to Pitts (1993). Solar radiation on the Canary Islands is three times more likely to induce cataract than in Stockholm. Whereas a 50\% reduction of the ozone concentration would increase the risk two-fold (Table 1 and Table 2).

As the sun rays continue traveling through the atmosphere, they enter the troposphere where they are scattered and attenuated by clouds and air pollution. Although this attenuates direct solar radiation, it may increase the global UVR due to wide angle scattering which is determined by the degree of cloudiness. Landscape and vegetation have the final influence on how much radiation is received by the earth's surface (Figure 7).

\subsubsection{Social aspects}

The lifestyle in developed countries has changed rapidly during the last 50 years. Weeks of holiday time and almost unlimited mobility have become the norm. And because sun-bathing and holidays in warmer climates are very popular, people are traveling more often to tropical latitudes. During a holiday to the Canary Islands a Stockholm resident gets three times as much exposure to UVR-B as at home (Table 1).

Although urbanism and a primarily indoor work environment decreased the general exposure to solar radiation overall, it may lead to a lower tolerance to UVR. Improved living standards, and increased use of drugs, and artificial components in our environment have ead to an increase in allergies and may also increase the susceptibility to photosensitizers.

Increased use of artificial sources of UVR also contributes to the environmental UVR dose. The quest for beauty (tanning booths), medical and industrial applications (chemical industry, disinfection), and black lights (insect traps, discotheques) are common today. Last but not least, increased life-expectancy increases the total amount of UVR one is exposed to over one's lifespan.

\subsection{Ocular sunlight exposure and corneal transmission}

\subsection{Ocular sunlight exposure}

The level of ambient solar UVR is most commonly expressed as the irradiance on the horizontal earth surface. Only a fraction of this irradiance, however, reaches the anterior human eye. O ur facial geometry, especially the eyebrows and eyelids protect our eyes from the direct solar rays. We also avoid exposure with a downward normal line of sight of $15^{\circ}$ (Sliney 1995). The reflective properties of the ground must also be considered. For example, grass reflects only 1 to $5 \%$ UVR whereas fresh snow may reflect up to 88\% (Sliney 1986). 
The relationship between the irradiance on the earth surface and ocular exposure is described by the ocular-to-ambient exposure ratio (Rosenthal et al. 1988b). Rosenthal et al. found this ratio to be between 2 and 17\%, depending on clothes, working conditions, and time of the year.

Use, size, and shape of sunglasses, as well as their distance from the eye, are other factors that make ocular exposure difficult to estimate (Rosenthal et al. 1988a). Lateral ocular exposure may cause lens damage, as well as temporal rays which may be focused into the lens by the cornea. This latter occurrence is known as the Coroneo effect (Coroneo et al. 1991) against which common sunglasses do not protect.

Several approaches have been tried in an attempt to measure ocular exposure more directly, for instance by using dolls or by placing UVR sensitive film at different positions on the heads of subjects. An interesting approach to ocular dosimetry is the use of contact lenses with Columbia Resin 39 or polysulphone as applied by Sydenham (1995). Employment of such contact lenses will supply dosimetry data directly from the corneal plane, allowing calculation of distinct values for the ocular-to-ambient exposure ratio under different conditions.
Merriam used computer ray tracing and mechanical models of the human eye to study the refraction of light by the comea and lens (Merriam 1996). He found that the concentration of light within the lens increases with angle of incidence and that the inferior and inferonasal lens receives more solar radiation than other sections of the lens.

\subsubsection{Comeal transmission}

To understand the in vivo injurious effect of UVR on the lens, knowledge on the transmission properties of the comea is important. Dillon et al. (1999) measured the transmittance of the cornea in the mouse, rat, rabbit and human with a spectrometer, using fiber optics (Figure 11). At 300 $\mathrm{nm}$, the transmittance of the mouse and rat comea, and of the rabbit and human cornea are very similar. This is probably due to the comparable thickness of the cornea of both pairs of species (Table 3).

The data from Figure 11 were also utilized to estimate the amount of UVR used in this study that would reach the lens of the rat and human Figure 23).

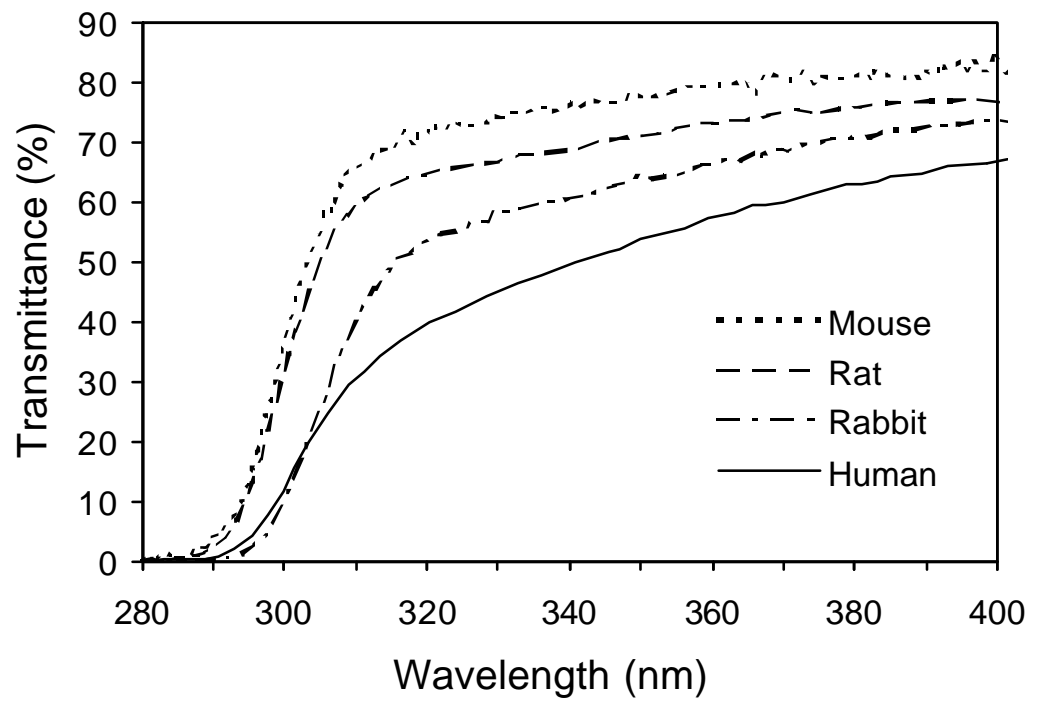

Figure 11.

Typical transmission spectra for a mouse, rat, rabbit and human cornea.

(Reprinted, with permission, from D illon et al. (1999). C opyright by A cademic Press, L ondon.) 


\begin{tabular}{lccccc}
\hline & $\begin{array}{c}\text { Corneal thickness } \\
(\mu \mathrm{m})\end{array}$ & $\begin{array}{c}\text { Corneal } \\
\text { transmittance } \\
\text { at } 300 \mathrm{~nm}(\%)\end{array}$ & $\begin{array}{c}\text { Corneal } \\
\text { transmittance } \\
\text { at } 380 \mathrm{~nm}(\%)\end{array}$ & $\begin{array}{c}\text { Anterior } \\
\text { chamber depth } \\
(\mathrm{mm})\end{array}$ & $\begin{array}{c}\text { Eye globe anterior - } \\
\text { posterior diameter } \\
(\mathrm{mm})\end{array}$ \\
\hline Mouse & $90 . .100^{1,2}$ & $37^{2}$ & $81^{2}$ & $0.45^{1}$ & $3.4^{1}$ \\
Rat & $120 . .160^{2,3,4,5}$ & $32^{2}$ & $76^{2}$ & $0.70^{5}$ & $6.3^{5}$ \\
Rabbit & $380 . .400^{2,6}$ & $13^{2}$ & $71^{2}$ & $3.50^{7}$ & $16.0^{7}$ \\
Human & $530 . .550^{2,6}$ & $10^{2}$ & $63^{2}$ & $3.50^{7}$ & $24.0^{7}$ \\
\hline
\end{tabular}

Table 3.

$\mathrm{D}$ imensions of the anterior eye of different mammals and corneal transmittance at two wavelengths in the UV R.

1 (Remtulla \& $\mathrm{H}$ allett 1985)

2 (D illon et al. 1999)

3 (Sandvig et al. 1997)

\author{
4 (Behar-C ohen et al. 1998) \\ 5 (Chaudhuri et al. 1983) \\ 6 (Li et al. 1997)
}

\section{7 (D avson \& G raham 1974)}

\subsection{Earlier research on ultraviolet radiation and cataract}

The transmission properties of ocular tissue were first scientifically investigated in the middle of the 19th century (Brücke 1845, DeChardonnet 1883). In Stockholm, at the beginning of the 20th century, Widmark compared the ocular injury occurring in people who have been struck by lightning with reports of snowblindness (photokeratitis) as well as with experiments by Hess (1868) who placed electrical discharges close to the eyes of rabbits. Widmark noticed similarities in the ocular damage and, knowing that UVR is produced by an electrical discharge, he postulated that UVR caused photokeratitis. From these findings, he speculated that ultraviolet radiation damages the comea and lens (Widmark 1889).

Widmark tested this theory by exposing a pig lens placed on his arm to UVR from a carbon arc lamp. After exposure, his skin showed severe erythema except in the place that had been covered by the pig lens. He then postulated that the radiant energy of the UVR absorbed by the pig lens damages the lens (Widmark 1891). In later experiments in rabbits, he found lens epithelial damage and swollen lens fibers, but no damage of the lens equator, following controlled exposure to UVR (Widmark 1901).
Verhoeff et al. gave a review of the knowledge concerning "the pathological effects of radiant energy upon the eye" at the beginning of the 20th century (Verhoeff et al. 1915/ 16). Since that time, there have been many experimental investigations and epidemiological studies of a possible relationship between UVR and cataract.

Epidemiological studies have the advantage of investigating the influence of UVR exposure over the long term, with results which can be directly applied to the human in a general sense. It is still difficult, however, to calculate the dose of UVR exposure for each individual subject over decades of exposure. Although dosimetry in experimental exposure on animals can be well controlled and cofactors for cataract can be excluded, the results must then be translated to the human.

\subsubsection{Epidemiology of cataract}

Epidemiological cataract research has always been challenged by the variety of factors influencing cataract development and by the difficulty of quantitative measurement of the optical properties in vivo. 
Zigman et al. (1979) compared the prevalence of cataract in Manila, Florida, and New York and grouped the individuals according to primarily outdoor or indoor activity. $\mathrm{He}$ found no dependence of cortical cataract on latitude ("more sunlight"), however there was such a dependence for brunescent cataract. Later, Brilliant et al. (1983) found a negative correlation between altitude, and a positive correlation between sunlight hours, and cortical cataract.

Taylor (1990) looked at 800 waterman in the Chesapeake Bay study. He estimated the individual UVR dose for each subject and found a correlation between individual UVR-B dose and cortical cataract. Cruickshanks et al. (1992) found only for male subjects a similar correlation in the Beaver Dam study. Bochow (1989) also linked posterior subcapsular cataract to UVR-B in a case-control study in Maryland. West et al. (1998) found an association between ocular exposure and increasing odds of cortical opacity, despite the relatively low ocular exposure to UVR-B in the population investigated. This carefully designed study, the Salisbury Eye Evaluation project, included 2520 community-dwelling elderly people.

Follow-up investigations of the Beaver Dam study (Klein et al. 1992) and of the Chesapeake Bay study (Schein et al. 1994) found an association of cortical cataract with the inferonasal quadrant of the lens. Also other studies report that cortical opacities were found more often inferonasal than elsewhere in the lens (Adamsons et al. 1991, Sasaki 1997). It would be difficult to explain this finding on the basis of nutritional, metabolic or aging effects. But the finding favors the theory that this type of cataract is caused by solar radiation.

There are a few reported cases in which people who received significant UVR doses from artificial sources subsequently developed cataract which could be correlated to this exposure. Lerman reported three patients who received $0.3-0.4$ $\mathrm{W} / \mathrm{m}^{2} \operatorname{UVR}(a=300-400 \mathrm{~nm})$ for about $200 \mathrm{~h}$ over an 18 month period related to their occupation. He found posterior subcapsular and zonular cortical opacities in one or both eyes of the patients (Lerman 1980).

Müller-Breitenkamp reported anterior and posterior subcapsular opacities in both eyes of a 65-year-old patient 30 years after unintended exposure to UVR. The patient received $0.7-2 \mathrm{~kJ} / \mathrm{m}^{2} /$ day UVR-B and $\mathrm{C}$ during the winter season over 15 years. The time that had elapsed since exposure was confirmed by measuring the distance between the lens capsule and the cortical opacities (Müller-Breitenkamp et al. 1997).

\subsubsection{In vivo experiments}

UVR-B is known to have a higher potential to damage the lens than UVR-A (Jose \& Pitts 1985, Wegener 1994). Exposure to $30 \mathrm{~kJ} / \mathrm{m}^{2}$ UVR-B in vivo induces an exponentially declining increase of sodium in the lens $\left(t_{0.5}=38 \mathrm{~h}\right)$ and a concomitant decrease of potassium which leads to a transient net increase of solute concentration peaking around $24 \mathrm{~h}$ after exposure (Söderberg et al. 1989). The increase of solute leads to an uptake of water that also peaks $24 \mathrm{~h}$ after exposure (Söderberg 1989). In parallel, the intensity of forward light scattering increases exponentially declining $\left(\mathrm{t}_{0.5}=19 \mathrm{~h}\right) \quad$ (Söderberg 1990b). Morphologically, these events correspond to swelling and disruption of first lens epithelial cells and later cortical lens fibers (Breadsell et al. 1994, Schmidt et al. 1988, Schmitt 1988, Söderberg 1988, Wegener 1994).

Investigations of the UVR action spectra in the rabbit by Pitts et al. (1977) showed that the wavelength $300 \mathrm{~nm}$ is most cataractogenic. The same group identified the UVR dose of $5 \mathrm{~kJ} / \mathrm{m}^{2}$ at $300 \mathrm{~nm}$ as the threshold for permanent lenticular damage. The dose-response for cataract after in vivo UVR-B was investigated by Söderberg and Löfgren (1994). They found the damage after UVR to be proportional to the logarithm of the dose.

Chronic exposure to UVR-A can induce epithelial damage and abnormalities in the anterior pole (Zigman et al. 1991). 


\subsection{In vitro experiments}

In vitro exposure of bovine, rabbit, and human lenses to UVR also lead to cataract formation and caused epithelial cell damage and decreased enzyme activity (Andley \& Weber 1995, Andley et al. 1990, 1994, Stuart \& D oughty 1995). The effects of UVR$A$ and $B$ on cultured animal lenses were compared by Hightower et al. (1993) and by Stuart et al. (1994). Both found a much greater response to UVR-B than UVR-A. Cultured bovine lenses showed a significant decrease in transmittance one week after a dose of $0.6 \mathrm{~kJ} / \mathrm{m}^{2}$ UVR-B, but not after a dose of $0.3 \mathrm{~kJ} / \mathrm{m}^{2}$. In cultured rabbit lenses, $30 \mathrm{~kJ} / \mathrm{m}^{2}$ UVR-B induced opacification (the lenses "became opaque"), whereas $3 \mathrm{~kJ} / \mathrm{m}^{2}$ had "little effect" one day after exposure. Significantly higher doses of UVR-A had no detectable effect on transmittance (Stuart: $14.4 \mathrm{~kJ} / \mathrm{m}^{2}$ after 20 days and Hightower: $240 \mathrm{~kJ} / \mathrm{m}^{2}$ after 4 days).

\subsection{Current estimation of risk for cataract}

Most cataracts develop as a gradual increase of lens opacity. Despite this, the estimations of risk for cataract today are founded upon the idea that cataract develops as a binary event. Furthermore, current exposure limits for UVR are based on subjective observations with slit lamp microscopy.

Most often, acute toxic effects are expressed as percent incidence occurring in an exposed population (Brown 1980). The dose causing a certain incidence of effect is called 'Effective D ose' (ED). The percentage of the population showing the effect is given as subscript. For example, if an effect is produced in $10 \%$ of the exposed population, it is written as ED 10.

The most common method for estimating the Effective Dose is the so-called Probit Analysis, developed by Finney (1971). This method, based on a quantal response, describes 'effect' or 'no effect' after a certain dose of a toxic agent.
The response is illustrated by plotting the proportion of the sample responding (ordinate) as a function of dose (abscissa). Such dose-response curves have a sigmoid shape. In Probit Analysis, the ordinate is substituted by a Probability Unit ('Probit') and the abscissa is converted to log-scale (Brown 1980, Finney 1971). By doing so the sigmoid curve is transformed into a straight line, and the Effect D ose for different percent of incidence can be easily estimated.

\subsubsection{Exposure limits for UVR}

O ne way to compare the biological effectiveness of UVR sources which have different spectra is the use of the erythemal action spectrum adopted by the Commission Internationale de l'Eclairage (CIE Research Note 1987) (Figure 12).

The American Conference for Governmental and Industrial Hygienists (ACGIH, USA) has adopted a relative spectral effectiveness curve for UVR (Figure 12) which is also recognized by the International Radiation Protection Association (IRPA). Ocular action spectra data upon which this effectiveness curve is based originate from the experiments of Pitts et al. (1977). They exposed the eyes of rabbits to UVR of increasing doses and at various wavelengths and then observed the cornea and lens with a slit lamp microscope. Using a qualitative grading system, the highest dose with no visible or only a limited number of damage signs was estimated as threshold for damage to the cornea and lens (Pitts et al. 1977).

Based on these experiments, Pitts published relative spectral effectiveness data for the cornea and the lens (Pitts 1993). His findings concerning the rabbit are given in Figure 12. Knowing the absolute effectiveness at the peak of the relative curve and the absolute spectral data for a given radiation source, it is possible to calculate the duration of safe exposure to that source (Pitts 1993). Results of such calculations for solar radiation are given in Table 1 and 2. 


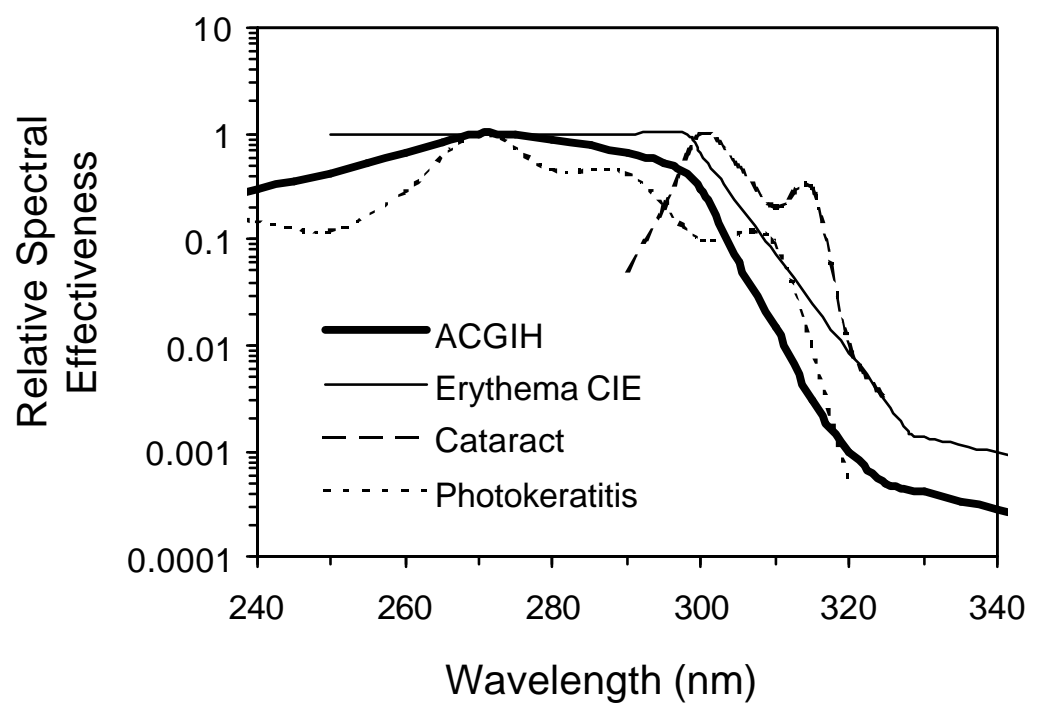

It should be noted that the threshold for photokeratitis is lower than that for cataract (legend of Figure 12). However, cataract is a late response with cumulative tendency while corneal UVR damage is an immediate response. "Thus repetitive ultraviolet exposures, though subthreshold for the comea may well lead to cataract in the long run" (Bachem 1956).

\section{Figure 12.}

Relative effectiveness of $U V R$ for the human as adopted by ACGIH (1996), relative effectiveness to induoe erythema as adopted by CIE (CIE Research N ote 1987) and relative effectiveness of UVR for cataract and photok eratitis for the rabbit by Pitts (1993). The minimum dose to induoe erythema is about $250 \mathrm{~J} / \mathrm{m}^{2}$ below $300 \mathrm{~nm}$ (depending on skin type and adaptation). The radiant ex posure threshold for photok eratitis and for the A CG IH spectrum is $30 \mathrm{~J} / \mathrm{m}^{2}$ at $270 \mathrm{~nm}$ and for cataract it is $1.5 \mathrm{~kJ} / \mathrm{m}^{2}$ at $300 \mathrm{~nm}$. $\left(1 \mathrm{~kJ} / \mathrm{m}^{2}=100 \mathrm{~mJ} / \mathrm{cm}^{2}\right)$ 


\section{AIMS OF THE STUDY}

The aims of this study were to:

$\square \quad$ find the optimal time point for detection of UVR-induced cataract

$\square \quad$ determine the dose-response function for UVR-induced cataract

$\square \quad$ develop a method for experimental estimation of the risk that UVR will induce cataract

$\square \quad$ investigate the effect of fractionation of UVR dose on cataract development

$\square \quad$ study apoptosis in the lens after UVR exposure

$\square \quad$ investigate the development and recovery of lens damage after UVR exposure

$\square \quad$ estimate the refractive index distribution in the lens several weeks after UVR exposure 


\section{METHODS}

\subsection{Experimental animals}

Young adult female Sprague-Dawley rats (6 weeks old, mean body weight $165 \mathrm{~g}$ ) were selected for all experiments. This age group was chosen to conform with an earlier short-term follow-up-study (Söderberg 1990b). At the most extended postexposure time (32 weeks), the animals were 38 weeks old, which is about one third of the rat's natural lifespan under laboratory conditions (Waynforth \& Flecknell 1992).

The rat eye is in many respects different from that of the human. Most important for the present studies are the dimensions of comea and lens (Figure 13).

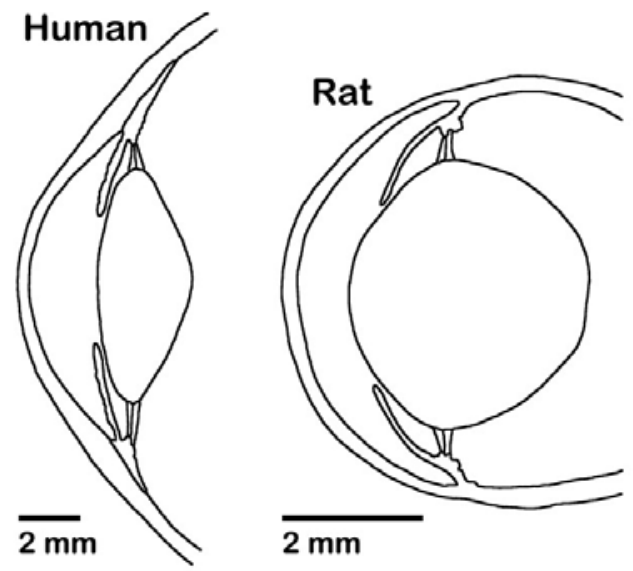

Figure 13.

C ross-section of the anterior eye of the human and the rat, drawn from histological sections.
The human comea is about five times thicker than the rat cornea and therefore transmits less UVR (Figure 11 and Table 3). The rat lens is not as flat as the human lens (Figure 13) and the rat lens does not change its shape by accommodation. However, the general structure, growth pattern and the proteins are comparable in the rat and the human lens.

Unpigmented rats are used in the present studies. The pigmentation of the animal's lens cortex and nucleus should be of minor importance because the UVR-B as applied in the experiments is already absorbed in the very first layers of the lens (Hightower et al. 1994, Söderberg et al. 1998). In contrast, UVR-A is penetrating much deeper into the lens and some parts of this radiation are transmitted by the lens (Boettner \& Wolter 1962, Lerman 1984). Therefore the pigmentation is more critical in studies of UVA-radiation (Zigman et al. 1991).

Ten minutes preceding each UVR exposure, the animal was anesthetized by intraperitoneal injection of a mixture of $94 \mathrm{mg} / \mathrm{kg}$ Ketamine and $14 \mathrm{mg} / \mathrm{kg}$ Xylazine. Five minutes after injection, Tropicamide was instilled in both eyes. After another 5 minutes, the eye was exposed to UVR for 15 minutes. The animal was exposed with a narrow beam which covered only the comea and the eyelids of the exposed eye.

The animals were kept and treated according to the Association for Research in Vision and Ophthalmology Statement for the Use of Animals in Ophthalmic and Vision Research. 


\subsection{Radiation exposure equipment}

The exposure system used in the experiments of Appendix I, II, V, VI and VII was based on the principle of Köhler's illumination Figure 14a) and was developed by Söderberg (1990a). A high pressure mercury lamp (HBO $200 \mathrm{~W}$, O sram, Germany) was the radiation source. A spherical reflector was placed behind the lamp to collect and concentrate the radiation from the backward direction. In the forward direction, the radiation passed through a water filter which absorbed infrared radiation. The radiation then passed through a condenser system including a 300-nm-interference filter with a half band width of $10 \mathrm{~nm}$. Behind this, the field aperture for the final beam was placed. The intensity of the final beam was controlled by a diaphragm in front of the projection lens.

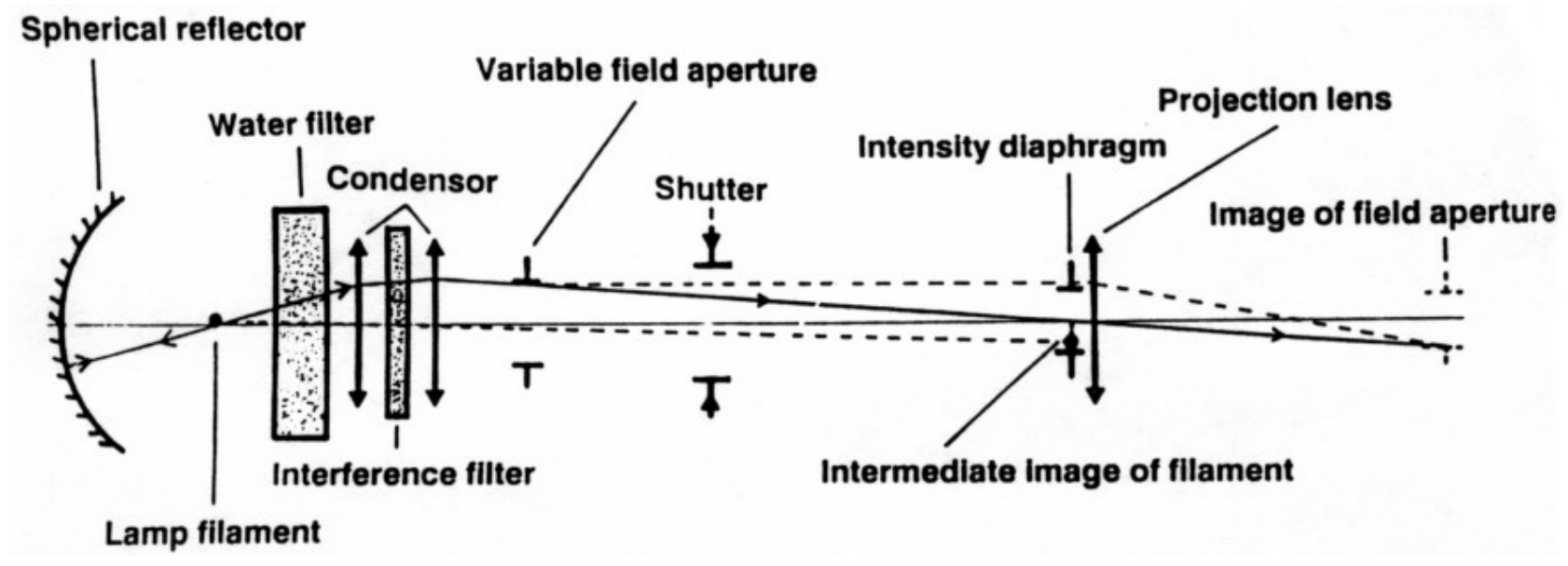

Figure 14a.

Principle of the interference-filter-based ex posure source (A ppendix I, II, V , V I, V II).

(R eprinted, with permission, from Söderberg (1990a). C opyright by M unk sgaard International Publishers, C openhagen.)

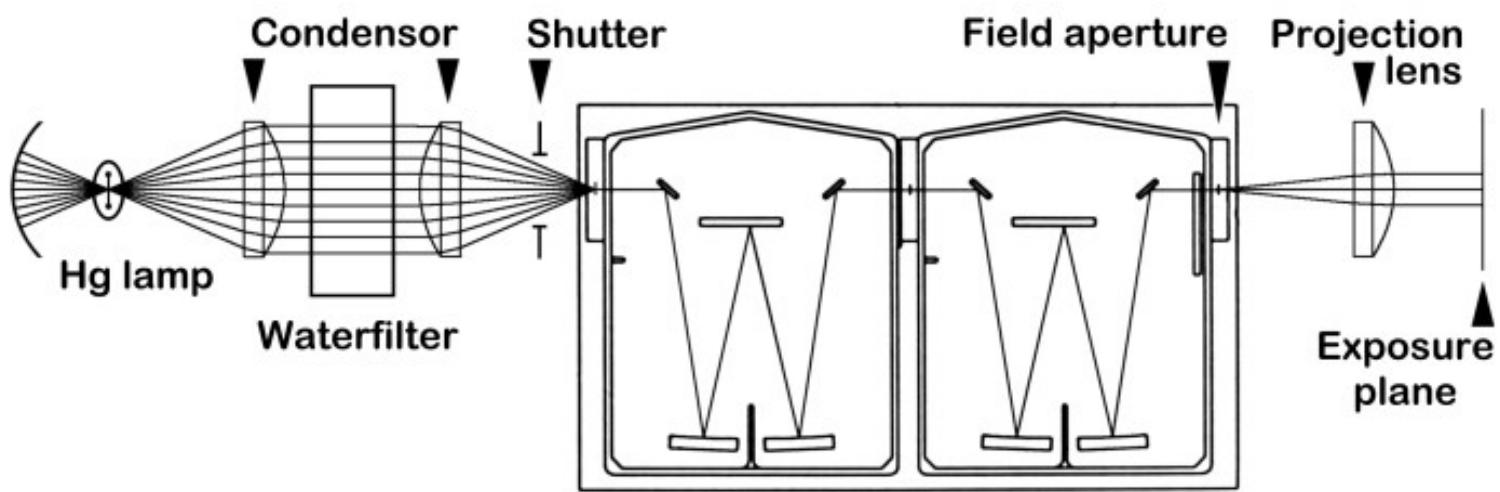

Monochromator

Figure 14b.

Principle of the monochromator based ex posure source (A ppendix III and IV ). 
For the experiments described in Appendix III and IV, a new exposure system was designed (Figure 14b). Here, the radiation from a high pressure mercury lamp (350 W, Oriel 6286) was collimated and passed through a water filter and a double monochromator (Oriel $2 \times 77$ 250) before being projected to the comea of the exposed eye. The monochromator was set to a wavelength of $300 \mathrm{~nm}$ and the entrance and output slit were adjusted to achieve a full width at half maximum of $9 \mathrm{~nm}$.

The spectral distribution of both exposure systems was measured with a fiber optic spectrometer (Ocean Optics PC 2000) and is given in absolute values of spectral dose and irradiance for a total dose of $5 \mathrm{~kJ} / \mathrm{m}^{2}$ (Figure 15).
The spectra were not symmetrical, as would be expected with radiation passing through an interference filter or monochromator. The reason for that is the line shape spectrum of the mercury discharge. Because of an intense mercury line at $302 \mathrm{~nm}$, the maximum intensity was found at this wavelength. Further lines from the mercury discharge at $297 \mathrm{~nm}$ and a strong line at $313 \mathrm{~nm}$ contributed to the spectrum. It should be noted that the radiation spectrum behind the monochromator is more narrow than behind the interference filter (Figure 15).

D uring the experiment, the irradiance at the corneal plane was measured with a thermopile (7104, O riel, USA) with a sensitivity of $45.5 \mu \mathrm{V} /\left(\mathrm{W} / \mathrm{m}^{2}\right)$. The instrument was calibrated regularly by the Swedish National Bureau of Standards.

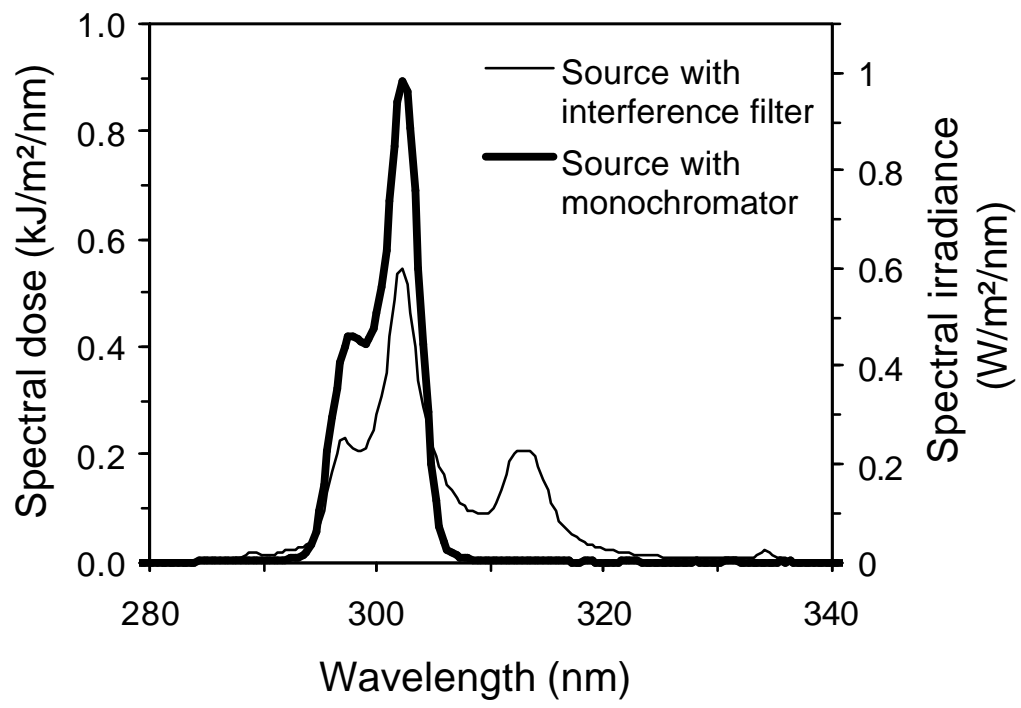

\section{Figure 15.}

Corneal spectral dose and irradiance for the interferencefilter- and mono-chromator-based ex posure source.

Both curves are absolute data for a total dose of $5 \mathrm{~kJ} / \mathrm{m}^{2}$ given during $15 \mathrm{~min}$. The resolution of the spectra is $1 \mathrm{~nm}$. 


\subsection{Light scattering measurements}

The intensity of forward light scattering is measured with the Light Dissemination Meter (Figure 16) developed by Söderberg (1990). This instrument uses the principle of dark-field illumination, in which the illuminating light transilluminates a transparent object at such a flat angle that it cannot enter the objective aperture. If the object contains scattering particles, the transillumination light is scattered (Figure 17a).

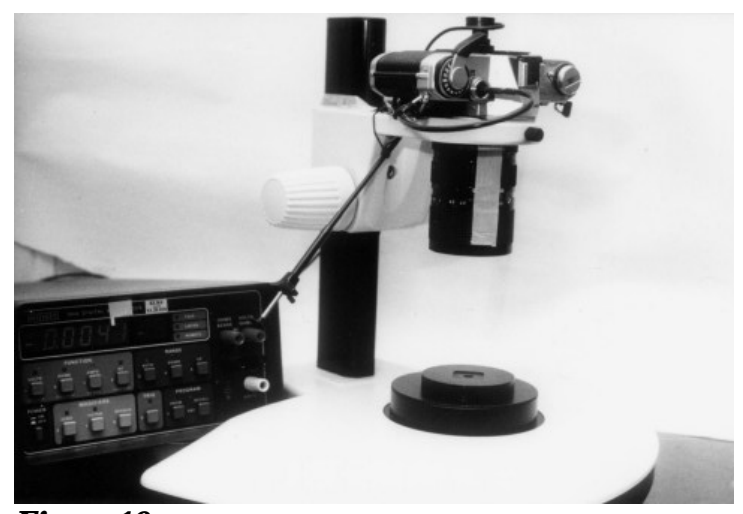

Figure 16.

Photographic view of the Light D issemination Meter with microsope basement (dark-field illumination), rebuilt photographic camera and A mpere meter on the left.
Light which is scattered in the forward direction at an angle of $45^{\circ}$ reaches the objective (Figure 17b). Light within an angle of $5^{\circ}$ is collected by the objective and is measured by a photodiode.

The scattering standard was a lipid emulsion of Diazepam (D iazemuls, KabiVitrum, Sweden), with the unit of measure, therefore, expressed as transformed Equivalent Diazemuls Concentration (tEDC) (Söderberg et al. 1990).

A typical value for a normal rat lens is about $0.1 \mathrm{EDC}$ and for a very opaque lens about 1 tEDC. The calibration curve in Figure 18 shows that the measured current from the photodiode increases linearly with the concentration of light scatterer (Diazemuls concentration) in the area of interest between 0 and $0.8 \mathrm{tEDC}$.

The minimum detectable difference of forward light scattering as measured with the Light D issemination Meter was $0.17{ }_{\mathrm{t}} \mathrm{EDC}$ for a sample size $\mathrm{n}=20$ and $0.20 \mathrm{t} E D C$ for $\mathrm{n}=15$ considering a $90 \%$ chance to detect a size difference between means with a significance level of 0.05 (Zar 1999b).
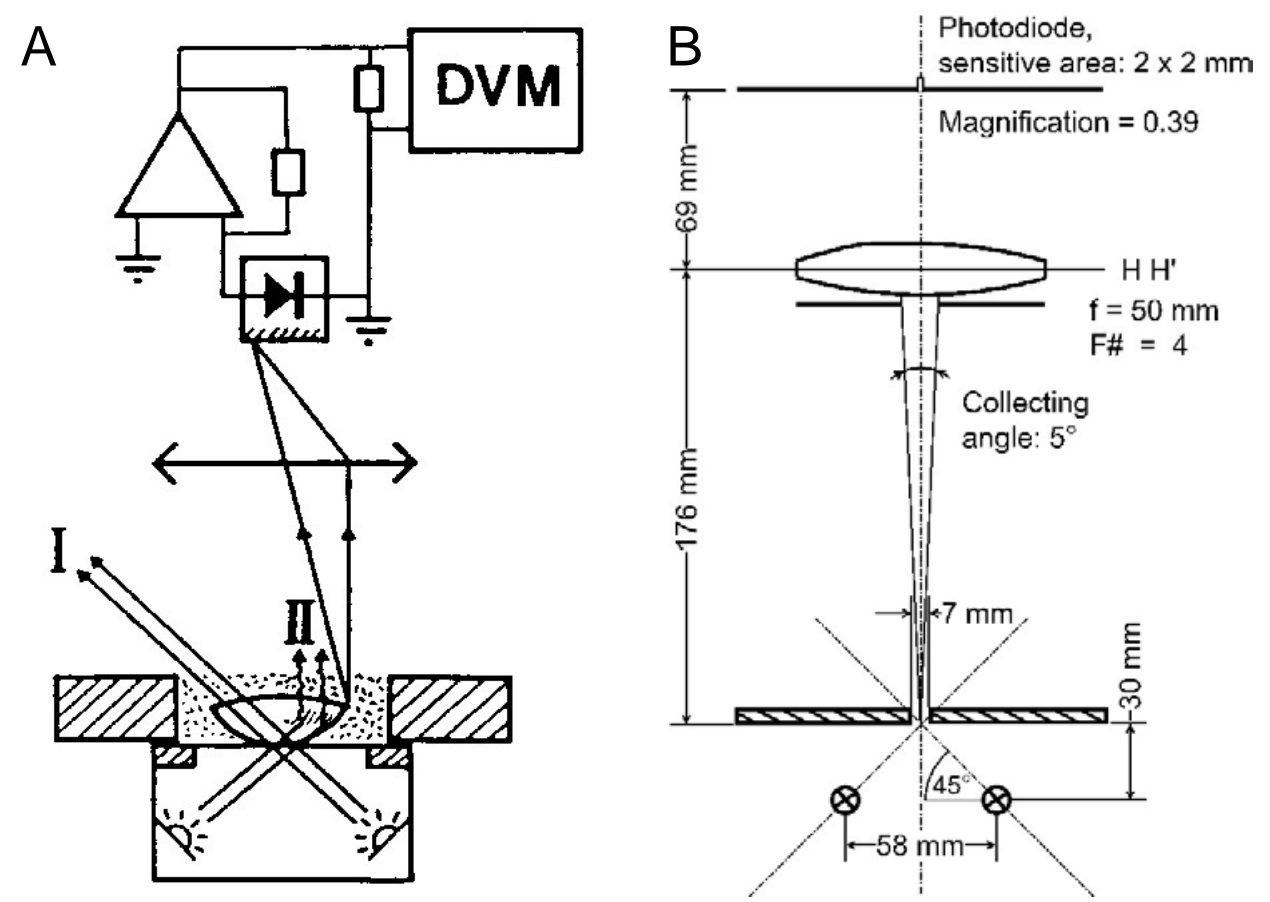

Figure 17a.

Schematic drawing of the L ight D issemination M eter. E x amined lens under darkfield illu-mination,

I = ideally clear lens, II = opacified lens, DV M = digital volt meter. (Reprinted, with per-mission, from Söderberg et al. (1990). Copyright by Munksgaard Inter-national Publishers, Copenhagen.)

Figure 17b.

Ray tracing of the Light $D$ issemination Meter with dimensions and optical properties. 


\section{Transformed Equivalent Diazemuls Concentration}

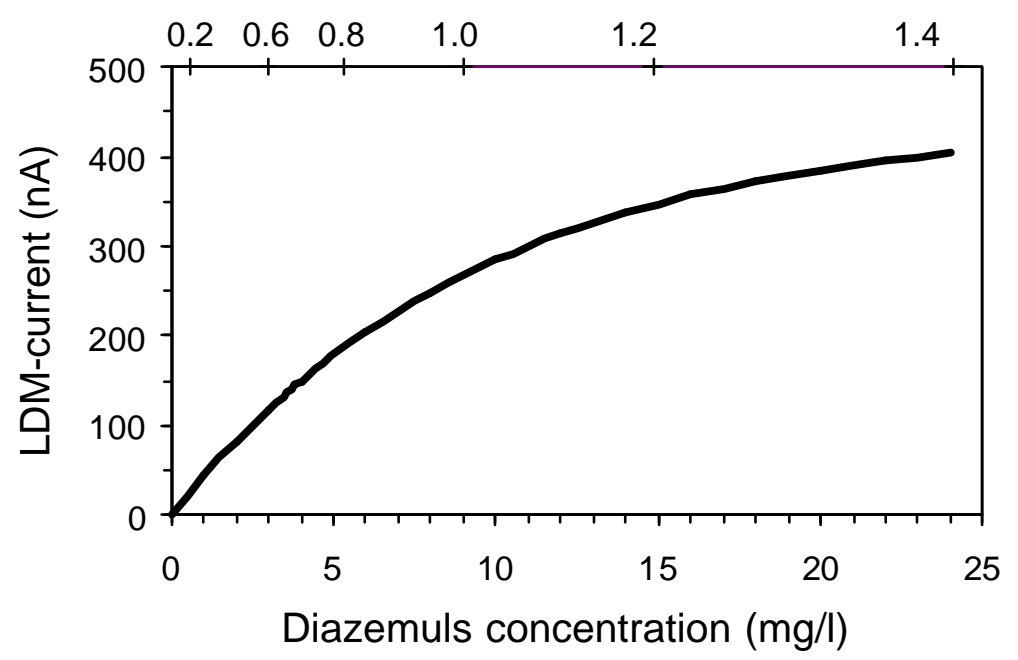

Figure 18.

Calibration curve for the L ight D issemination M eter.

\subsection{Microradiography and confocal microscopy}

\subsubsection{Laser scanning confocal microscopy}

The Laser scanning confocal microscope was employed for three different purposes in the current study. It was used in reflective confocal mode to image fluorescence from imuno-histochemical staining of TUNEL (Appendix V) and WGA (Appendix VI). This is by far the most common application of such microscopes, collecting the fluorescent signal only from a finite confocal layer.

Laser scanning confocal microscopes are less frequently used in transmitted non-confocal mode. Here, the feature of the scanning laser was utilized to measure the transmittance of a microradiogram point by point (Appendix VII). However, because the laser ray does not travel only through the central part of the microscope optics (as in a densitometer), vignetting occurs. Vignetting means intensity loss at the edge of images. In the current study it was minimized by careful adjustment of the scanning microscope. Measurements in background images revealed that the center-to-edge vignetting was always less than $3 \%$, making a planned image processing to compensate for vignetting unnecessary.

The Laser scanning confocal microscope can also be utilized to estimate the thickness of a specimen section (Brismar et al. 1996). Then, the microscope is operated in reflective confocal mode and the autofluorescence of the specimen section is imaged as a vertical profile image (Appendix VII, figure 4). In the current manuscript version of Appendix VII, the thickness estimations were not performed perpendicularly to the section. Therefore, the thickness was overestimated which results in a systematic underestimation of the protein density. However, because this is a systematic error, it should not influence the conclusions of Appendix VII, which are drawn from the comparison of the exposed and non-exposed lenses. 


\subsubsection{Microradiography}

It has been shown that there is a linear relationship between the refractive index and the concentration of unconjugated proteins in biological specimens (Barer \& Joseph 1954). Based on this, Lindström (1955) and Philipson (1969c) continued the development of contact microradiography for the estimation of the protein density in the crystalline lens.

In microradiography, the dry mass content of freeze-dried tissue sections is estimated. The tissue sections are placed on a metal disk together with a reference system (Figure 19). The X-ray film plate is placed behind the metal disk and is then exposed to continuous X-ray (Roentgen) radiation. The development of the film plate gives the microradiogram (Figure 19). After measuring the transmission of the microradiogram, the dry mass density in the specimen can be estimated by comparing it with the known mass of the standard film in the reference system (Lindström 1955, Philipson 1969c).

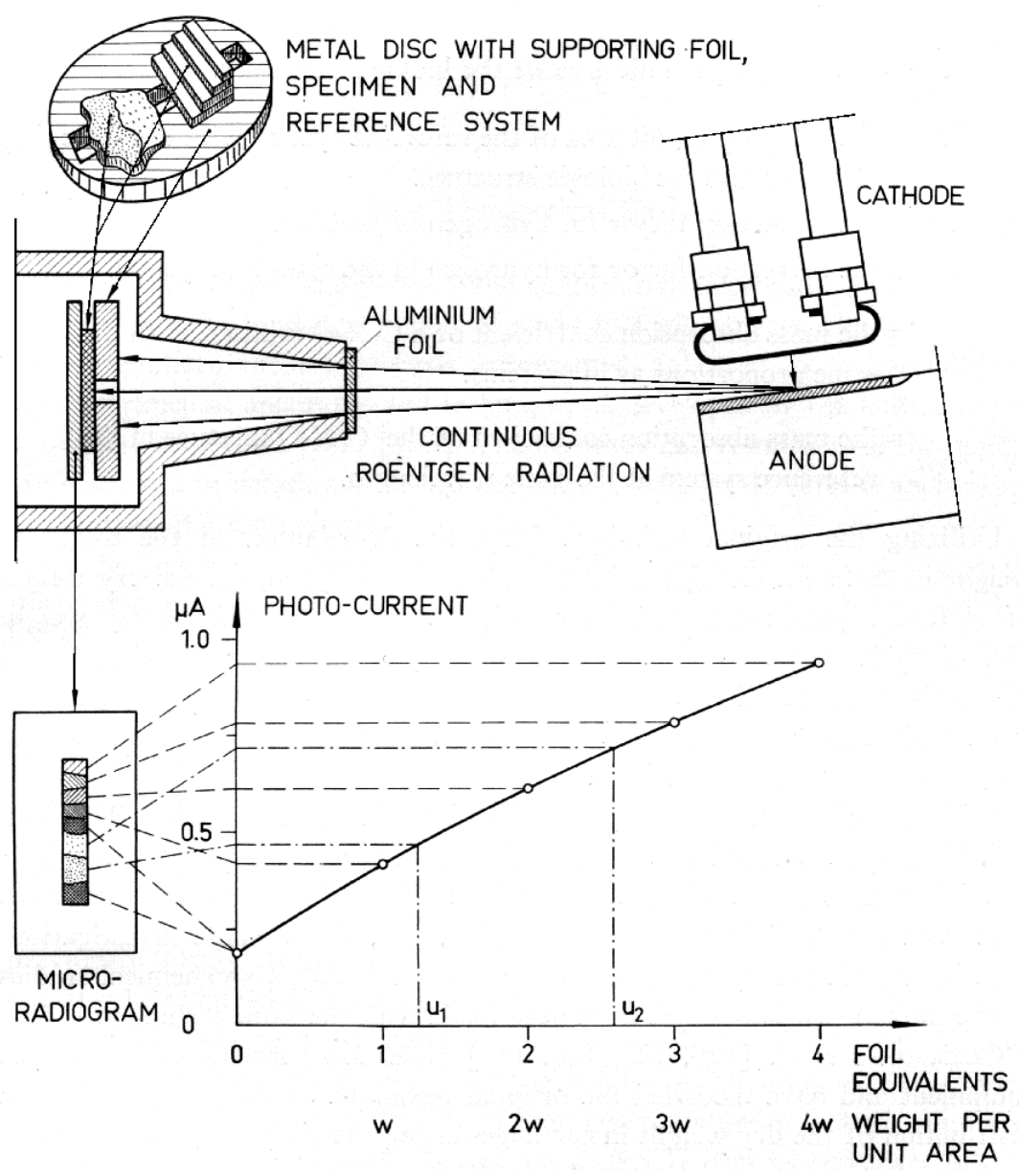

Figure 19.

Schematic representation of the quantitative microradiographic procedure to determine the total dry weight of small biologic objects. (Reprinted, with permission, from Lindström (1955). Copyright by Munksgaard International Pub-lishers, C openhagen.) 


\section{RESULTS AND DISCUSSION}

\subsection{Development of forward light scattering (I, II)}

The lens opacities have been quantitatively described based on the intensity of forward light scattering in the lens. The development of the forward light scattering between 1 and 32 weeks is described in Appendix I. The dose-response relationship of the forward light scattering is described in Appendix II.

\subsubsection{Time point for maximum light scattering}

It was found that the mean difference in intensity of forward light scattering between exposed lenses and their non-exposed contralaterals;

- does not change between 1 and 32 weeks after $5 \mathrm{~kJ} / \mathrm{m}^{2}$ UVR (Appendix I)

- reaches a maximum at one week after $20 \mathrm{~kJ} / \mathrm{m}^{2}$ UVR (Appendix I)

- has an exponentially declining increase up to one week after $30 \mathrm{~kJ} / \mathrm{m}^{2}$ UVR (Söderberg 1990b).

These observations indicate that further studies of lens damage should be conducted evaluating changes which occur one week after exposure to UVR. It was not previously known that lenses exposed to $20 \mathrm{~kJ} / \mathrm{m}^{2}$ UVR are totally destroyed four weeks after exposure (Figure 24). As explained in Appendix I, this resulted in a decrease of forward light scattering. Also, doses lower than $20 \mathrm{~kJ} / \mathrm{m}^{2}$ UVR should be employed in further studies, as it is not meaningful to damage the lens that severely.

\subsubsection{Possible repair of UVR-induced lens opacities}

A skewed distribution of the difference in forward light scattering is found at four weeks and later after exposure to $5 \mathrm{~kJ} / \mathrm{m}^{2}$ (Appendix I). In Appendix I, it is speculated that $5 \mathrm{~kJ} / \mathrm{m}^{2} \mathrm{UVR}$ may be a threshold dose for UVR-induced cataract. The idea is that a less intense reaction may occur below threshold and a more intense reaction above. The results of the dose-response experiment (Appendix II), however, show that this hypothesis must be discarded. It was found that the intensity of forward light scattering increases continuously with increasing UVR dose. As mentioned above, the skewed distribution did not appear immediately after the UVR exposure, but at four weeks after and later. This may indicate that lens damage increases continuously with increased UVR dose, but can be repaired only if the damage is limited.

As a follow-up of these ideas from Appendix I and II, the morphological development and repair of lens opacities after a dose of $5 \mathrm{~kJ} / \mathrm{m}^{2}$ was investigated and is described in Appendix VI.

\subsubsection{Dose-response after UVR exposure}

The intensity of forward light scattering in the lens increases along with UVR dose between 3 and $20 \mathrm{~kJ} / \mathrm{m}^{2}$. No significant change in intensity of forward light scattering was observed for lower UVR doses (Figure 20)(Appendix II). 
The left part of Figure 20 shows the mean difference in forward light scattering between the exposed and non-exposed lens one week after UVR exposure, as a function of the UVR dose applied. For UVR exposures between 0.1 and $14 \mathrm{~kJ} / \mathrm{m}^{2}$, an exponential function was found which best fit the dose-response data (Appendix II).
This exponential function probably represents the first part of a sigmoid function, which starts with an exponential increase, curves and flattens asymptotically (Figure 20). This idea is supported by the earlier findings of Söderberg and Löfgren (1994). They found a logarithmic dependence of forward light scattering on higher UVR doses (up to $300 \mathrm{~kJ} / \mathrm{m}^{2}$ ), which probably represents the second part of the sigmoid function.

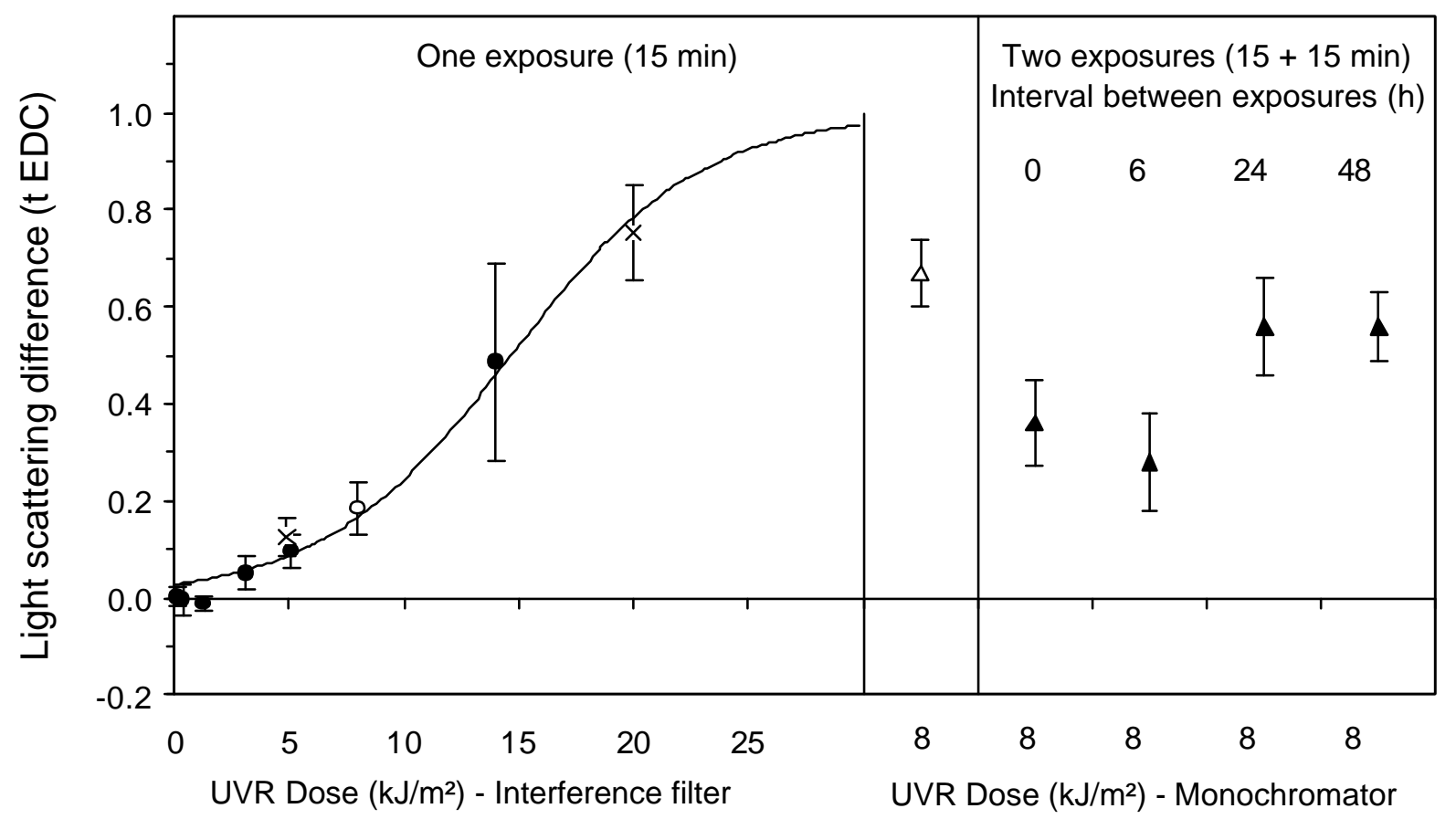

Figure 20.

The left part shows the doseresponse function for U V R induced cataract (solid line) from ex periments using the interferencefilter-based sourœ. The right part shows data from ex periments using the monochromator-based source. $\mathrm{N}$ ote that the ex posure dose of $8 \mathrm{~kJ} / \mathrm{m}^{2}$ induces different light scattering, dependent on the ex posure source and ex posure time.

X -symbols: data from the long-term ex periment (A ppendix I), Circles: data from the dose-response ex periment (A ppendix II)

0 pen triangle: data from an ex periment by L öfgren et al. (1997) and Solid triangles: data from the repeated ex posure ex periment (A ppendix IV ).

The data symbolized by a triangle were obtained simultaneously. D atapoints with open circle and open triangle were obtained with the same dose and same ex posure time, but different ex posure source. Bars are the $95 \%$ confidence interval for the mean difference of forward light scattering between the ex posed and non-ex posed lens one week after (the second) in vivo ex posure to U V R.

Sigmoid trendline: $\quad \mathrm{v}=\frac{1}{1+\mathrm{e}^{3.5524-0.2422 \cdot \mathrm{x}}}$ 


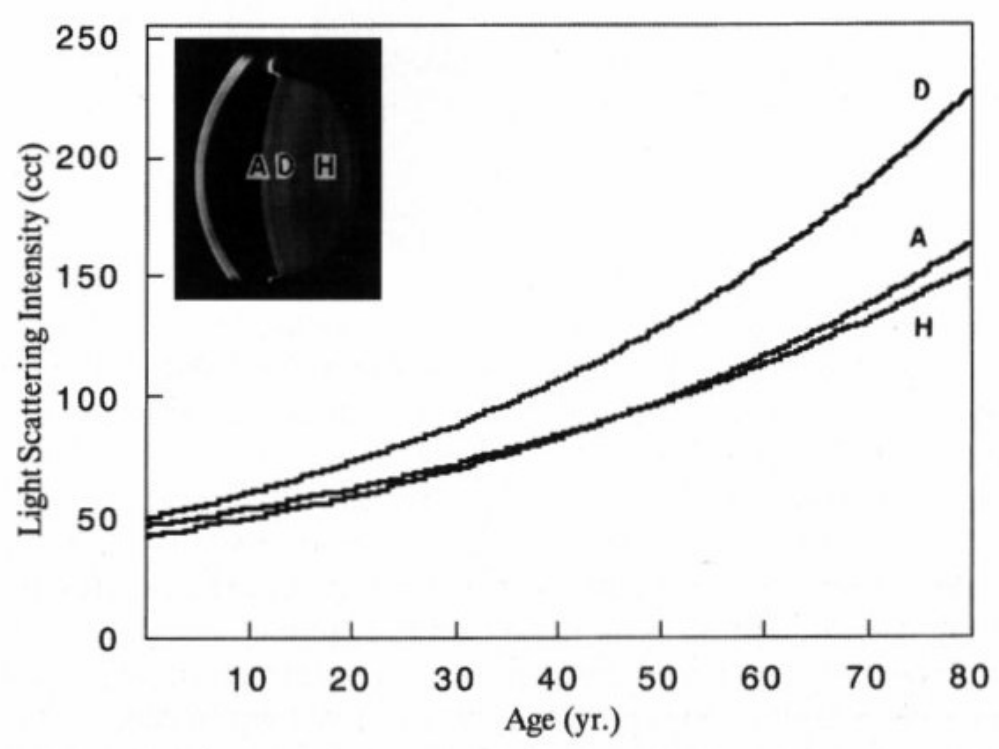

Figure 21.

Intensity of light scattering in representative lens layers as a function of age in humans.

(Reprinted, with permission, from Sasaki (1997). Copyright by N ova A cta L eopoldina, $\mathrm{H}$ alle.)
In an epidemiological study, Sasaki (1997) found an exponential increase of lens opacities with increasing age (Figure 21). This exponential increase was found for the entire lens, but was most pronounced for the lens cortex. It is interesting that lens opacities increase exponentially with age as well as with UVR dose. This might support the idea that finite lens damage induced by UVR accumulates over a lifetime and results in cortical cataract.

\subsubsection{Macroscopic model for the dose-response function}

There may be two types of idealized dose-response functions (Sliney \& Wolbarsht 1980b) which both can be modulated by repair. First, there may be a function with a threshold. Here, low doses induce no effect. At a certain dose there is a sharp increase of the dose-response function to the maximal response. Higher doses do not induce more response. Because of variations between individuals this dose-response function can become stochastically modulated. Then the probability for response as a function of dose has a sigmoid curve.
Second, there may be a continuous dose-response relationship. Here, increasing doses induce continuously more severe response. Any single exposure would have a finite effect and a cumulative exposure would increase the response. Then the response as a function of dose is a sigmoid curve.

If repair comes into play, e.g. with a continuos process, then below a certain dose there will be no effect. Above a certain dose, when the injury overwhelms the repair, the dose-response function continues as for the pure continuous process.

The results from Appendix II and the doseresponse function in Figure 20 show that very low UVR doses $\left(<1.3 \mathrm{~kJ} / \mathrm{m}^{2}\right)$ do not induce increased forward light scattering. For higher doses the doseresponse function has a sigmoid shape. This suggest that UVR lens damage is a continuous process with repair according to the above described idealized dose-response functions. 


\subsubsection{Microscopic model for the dose-response function}

One may assume that the crystalline lens is composed of an infinite number of units that may react with a quantal response to UVR, changing from clear to scattering. One may assume also that there is a threshold dose needed to switch from clear to scattering and that it varies randomly among the units.

Considering the central limit theorem*), it is reasonable to believe that the frequency distribution for threshold doses is normally distributed Figure 22). Then holds, that the proportion of scattering units after a certain dose is described by the integral of the frequency distribution of threshold doses (Figure 22).

If the lens with commencing cataract is simplified to an infinitely dilute solution, the total intensity of light scattering from a number of scattering units is directly proportional to the number of scattering units. Thus, the quantity on the

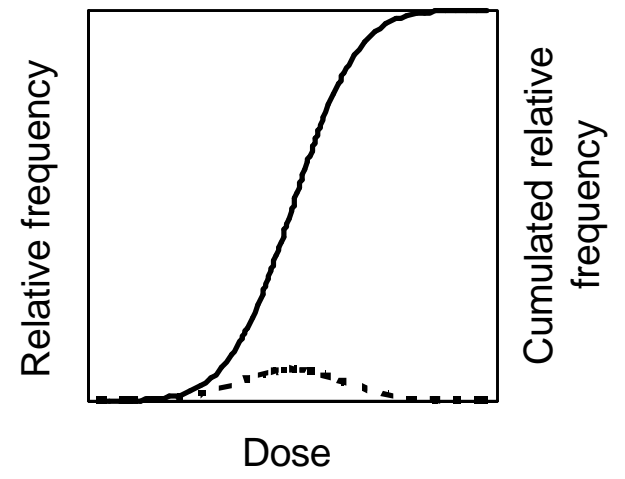

Figure 22.

Relative frequency (dotted line) and aumulated relative frequency (solid line) of scattering units in the lens as a function of dose of ultraviolet radiation.

right Y-axis in Figure 22 may be changed to total intensity of light scattering in a lens. The sigmoid shape of the cumulated relative frequency is indeed found in the doseresponse function for UVR cataract (Figure 20).

\subsection{Estimation of a Maximum Acceptable Dose (III)}

\subsubsection{Setting a lower limit for nomal lenses}

The level of light scattering of clinically clear lenses varies from individual to individual in accordance with the normal distribution (Söderberg et al. 1990). For this reason, the lower limit or beginning of pathologic light scattering must be defined statistically as the maximal level of light scattering that a certain fraction of normal clinically clear lenses expresses. In Appendix III, this fraction $\mathrm{p}$ was set to $97.5 \%$.

The selection of the fraction of unexposed lenses that shall count as clinically normal influences the Maximum Acceptable Dose (MAD). If a larger fraction of lenses were considered as clinically normal, the resulting MAD would be higher and more severe damage would be accepted. If a smaller fraction of lenses were be considered as clinically normal, the resulting MAD would be lower

and the toxicity estimation would be more conservative, with a lower acceptable dose and therefore less damage. In this way, selecting the limit for normal lenses incorporates the risk which will be accepted with a certain Maximum Acceptable D ose.

\subsubsection{Experimental dose-response function}

In search of an index for toxicity of UVR on the crystalline lens, only the low-dose-region of the dose-response function is of interest (Figure 20). In Appendix III, the sample size was 20 rats. Therefore, the estimates of the mean and variance of forward light scattering of normal clinically clear lenses have limited precision. With increasing sample size, the estimates would converge towards the expected values.

*) "If random samples of size $\mathrm{n}$ are drawn from a normal population, the means of these samples will conform to normal distribution. The distribution of means from a non-normal population will not be normal but will tend towards normality as $n$ increases in size. This result is known as the central limit theorem" (Zar 1999a). 


\subsubsection{Estimation of the Maximum Acceptable Dose}

The lower limit or beginning of pathologic light scattering is projected on the dose-response function obtained with the regression analysis of experimental data (Appendix III, Figure 4). The dose corresponding to that point can be estimated and was suggested to be called the Maximum Acceptable D ose (MAD).

\subsection{Fractionation of exposure (IV)}

\subsubsection{Influence of fractionation of exposure}

Estimating the biologically effective UVR dose is important for occupational safety standards, evaluating environmental UVR exposure, and in experimental studies. During continuous or intermittent long-term exposure, biological damage can accumulate, be amplified or be repaired; this has to be considered for the above estimation.

UVR doses repeated within different time periods may be said to be additive only if they produce the same effect as the sum of the doses without any interval between them. Duke-Elder and MacFaul (1972) stated that "... the effect of repeated exposures with intermissions is in a general sense equal to their equivalent as a single long exposure, provided that the intervals do not exceed 24 hours ...". O ccupational doses are often calculated by adding exposure doses within one day or an $8 \mathrm{~h}$ working day. In their guidelines of Threshold Limit Values for chemical substances and physical agents the American Conference of Governmental Industrial Hygienists (ACGIH 1996) considers UVR exposure within an $8 \mathrm{~h}$ interval to be additive. One of the few epidemiological studies which estimated the UVR dose over decades (Taylor et al. 1988) used a serial additive expecteddose model. In this model (Smith et al. 1980), the estimated exposure dose for one day was summed to determine annual exposure.

The experiment described in Appendix IV, fractionated the UVR exposure into two parts with $0,6,24$ or 48 hours between them. After two UVR exposures, forward light scattering by the rat lens is
The MAD 0.975 for rat lenses found in this study is of the same order of magnitude as the threshold for permanent cataract in rabbits as reported by Pitts et al. (1977). It should, however be kept in mind that the rabbit comea is thicker than the rat cornea and therefore should filter out more UVR (Table 3 and Figure 11).

the same whether the second UVR exposure is repeated immediately or after a $6 \mathrm{~h}$ interval (Figure 20). Therefore, UVR exposure doses applied within a $6 \mathrm{~h}$ time period are additive. When the second exposure follows 24 or $48 \mathrm{~h}$ after the first, forward light scattering is greater than after the shorter time intervals (Figure 20). UVR doses repeated after 24 or $48 \mathrm{~h}$ thus aggravate the injury and are not additive.

Why lens injury is greater when the second UVR dose follows 24 or $48 \mathrm{~h}$ after the first is not known. Defense against oxidative stress may be less effective or membrane function might be challenged after a UVR exposure (Hightower 1994, Shindo \& Hashimoto 1997). Therefore, arepeated UVR exposure may produce a more severe biological response. Another explanation for the increased susceptibility might be the formation of photoproducts (Hightower 1994) between 24 and $48 \mathrm{~h}$ post-exposure. Furthermore, programmed cell death peaks at $24 \mathrm{~h}$ after a low-dose-UVR exposure (Appendix V). Replacement of dead cells demands a higher rate of mitosis in the germinative zone and a second UVR exposure at that time may have a more damaging effect.

During the design of the experiment in Appendix IV, we expected a decrease of lens damage with increased time between the exposures. After having performed the experiment, we suspected that the maximum time between exposures (48 h) was too short to allow recovery and repair in the lens. Therefore, a new experiment was designed by Ayala et al. (2000) with two exposures separated by $0.25,1,3,9$ and 30 days. 


\subsubsection{Influence of exposure time}

Figure 20 includes also one datapoint from an experiment by Löfgren et al. (1997) from a study of the influence of age and gender on the formation of UVR cataract. We used the same dose of $8 \mathrm{~kJ} / \mathrm{m}^{2}$ from the monochromator-based source as in Appendix IV, but delivered during $15 \mathrm{~min}$ and not during $30 \mathrm{~min}$ as in Appendix IV. The same dose given during half the exposure time induces almost twice the forward light scattering as measured in $\mathrm{EDDC}$ (Figure 20).

This preliminary result questions the validity of the Bunsen-Roscoe reciprocity law (Bunsen \& Roscoe 1862) for UVR-induced forward light scattering. This law says that the amount of chemical change produced is proportional to the amount of light absorbed. In other words, the product of irradiance and time is constant and there is a time reversal symmetry. Even though the Bunsen-Roscoe reciprocity law is a photochemical law and was established based on experiments with photographic paper (Bunsen \& Roscoe 1862), it is widely applied in biology. In order to check if the Bunsen-Roscoe reciprocity law holds for UVR induced cataract, Ayala et al. (1999) designed a follow up experiment where the same exposure dose was given during exposure times ranging between 5 and $120 \mathrm{~min}$.

\subsubsection{Influence of radiation spectrum}

The summary diagram of Figure 20 also draws attention to the fact that the detailed spectral distribution is important for the biological response. The single dose of $8 \mathrm{~kJ} / \mathrm{m}^{2}$ delivered during $15 \mathrm{~min}$ induced more than twice the damage when it was given by the monochromator-based source as compared with the interference-filter-based source (Figure 20, open circle and open triangle).
The different spectra for the interference-filter-based and monochromator-based source are given in Figure 23. The corneal dose is the same for both absolute spectra, but the spectrum from the monochromator-based source is more narrow and therefore the radiation dose is more concentrated at $300 \mathrm{~nm}$. The spectral irradiance at $300 \mathrm{~nm}$ is about $50 \%$ higher behind the monochromator-based source as compared with the interference-filterbased source. Because the wavelength at $300 \mathrm{~nm}$ is known to be more damaging to biological tissue, this would explain the greater damage behind the monochromator-based source.

The erythemal dose according to the Commission Intemationale de l'Eclairage (CIE) is often used to compare the biological effectiveness, not only for erythema. The relative effectiveness for erythema by the CIE is given in Figure 12 and is used for calculation of the corneal dose from both exposure sources. The erythemal dose of $5 \mathrm{~kJ} / \mathrm{m}^{2}$ comeal dose is $2.0 \mathrm{~kJ} / \mathrm{m}^{2}$ for the interference-filter-based source and $3.0 \mathrm{~kJ} / \mathrm{m}^{2}$ for the monochromatorbased source. This again reveals the $50 \%$ more damaging impact of the monochromator-based source.

Figure 23 includes also an estimation of the dose that a rat lens as well as a human lens would receive during the experiments. Transmittance data for the rat and human cornea, as shown in Figure 11, were used for these theoretical estimations. The spectral difference of the radiation reaching the lens from the two sources, becomes even more pronounced after filtering by the cornea. 

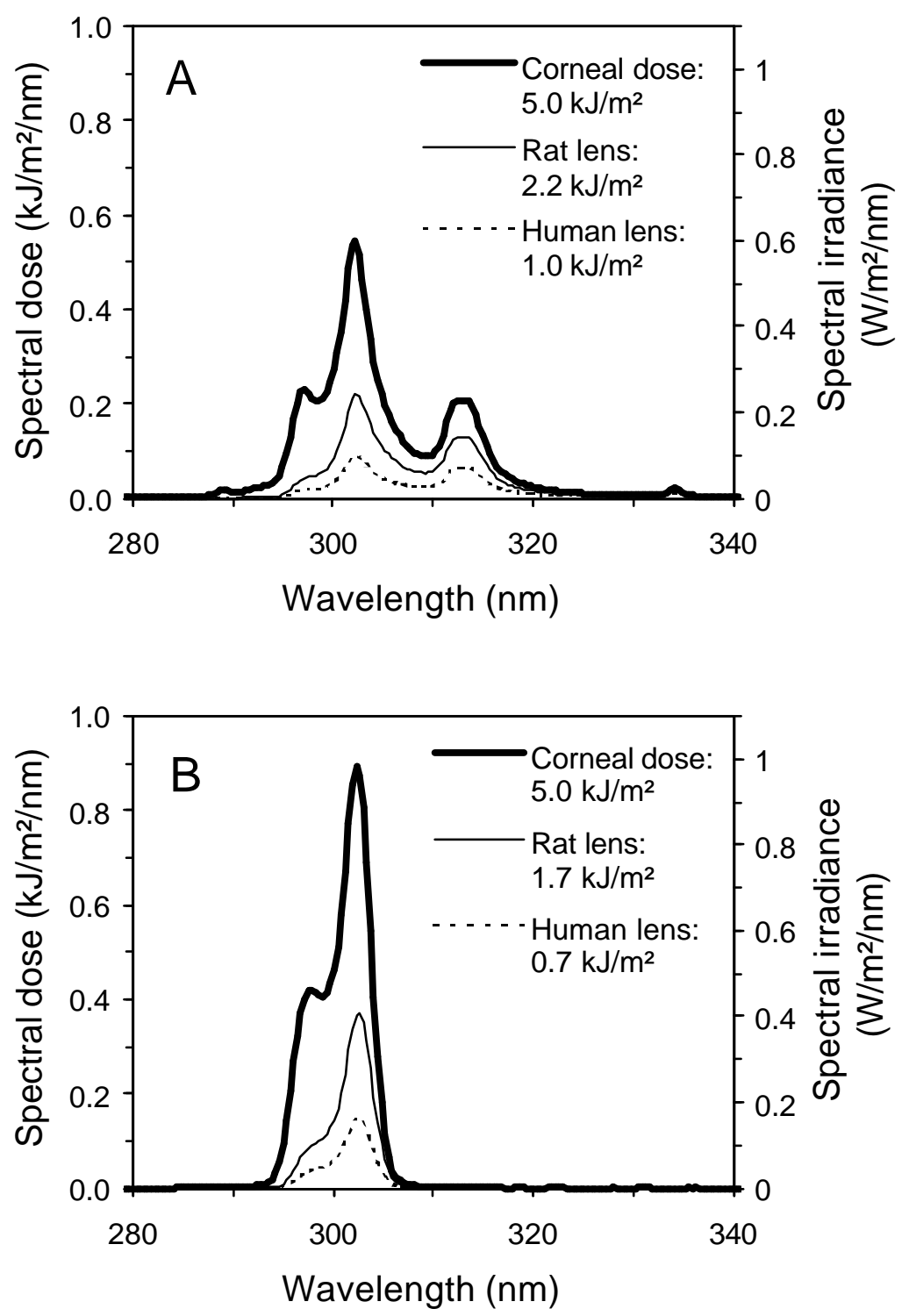

\section{Figure 23.}

Comparison of corneal dose and estimated dose reaching the rat lens and the human lens respectively.

Figure 23a shows this comparison for the interferencefilter-based source and Figure 23b for the monochromator-based source.

$\mathrm{D}$ ata from figure 11 used for estimating the dose reaching the lens. 


\subsection{Morphological changes and repair (V, VI)}

\subsubsection{Comea}

Ocular inflammation and corneal damage were recorded subjectively during the long-term experiment (Appendix I) (Table 4). Observational criteria for "O cular inflammation" were swollen eyelids, conjunctival injections and discharge. Corneal damage was categorized as superficial opacity, diffuse opacity, micro tumor and neovascularization.

All animal eyes exposed to $20 \mathrm{~kJ} / \mathrm{m}^{2}$ and $30 \%$ of those exposed to $5 \mathrm{~kJ} / \mathrm{m}^{2}$ went through an inflammation of conjunctiva and comea Table 4). All animal eyes exposed to $20 \mathrm{~kJ} / \mathrm{m}^{2}$ and $50 \%$ of those exposed to $5 \mathrm{~kJ} / \mathrm{m}^{2}$ got an opaque cornea between 4 and 7 days after exposure. Eyes exposed to the lower dose had less intense inflammation and comeal opacity. An ulcus remained on $50 \%$ of the corneas exposed to $20 \mathrm{~kJ} / \mathrm{m}^{2}$ at 28 days after exposure and thereafter. Blood vessels were observed on $70 \%$ of the corneas exposed to 20 $\mathrm{kJ} / \mathrm{m}^{2}$ and on $30 \%$ of those exposed to $5 \mathrm{~kJ} / \mathrm{m}^{2}$ between 4 and 32 weeks after exposure (Table 4).

Andley et al. (1996) found a similar time course for comeal and conjunctival damage in the rabbit after UVR exposure. The exposure dose was higher (28 $\mathrm{kJ} / \mathrm{m}^{2}$ ) but the radiation spectrum was more broad than that in the present experiment and had a maximum at $310 \mathrm{~nm}$.
The damage in the comea was observed between 1 and 3 days and in the conjunctiva between 1 and 4 days after UVR exposure.

\subsubsection{Intact lens}

O ne week after exposure to UVR, lens opacities are visible to the naked eye in lenses exposed to $3 \mathrm{~kJ} / \mathrm{m}^{2}$ or higher doses (Figure 24). Exposed lenses have haze on their anterior and posterior surface that becomes more intense with increased dose. After exposure to $14 \mathrm{~kJ} / \mathrm{m}^{2}$, the surface becomes opaque, strong equatorial opacities are visible, and the ciliary body is often attached to the lens. After exposure to $20 \mathrm{~kJ} / \mathrm{m}^{2}$ the cortical and equatorial opacities are more dense and nuclear opacities could be seen (Figure 24).

It is stated in the literature that following UVR exposure, "animal opacities mainly occur in the anterior cortical region of the lens whereas human cortical opacities tend to occur in the equatorial (peripheral) parts of the cortical region" (Dolin 1994). This might be the case a short time after experimental exposure to UVR, as seen one week after exposure in the current experiments Figure 24).

\begin{tabular}{|c|c|c|c|c|}
\hline Corneal dose & $5 \mathrm{~kJ} / \mathrm{m}^{2}$ & $5 \mathrm{~kJ} / \mathrm{m}^{2}$ & $20 \mathrm{~kJ} / \mathrm{m}^{2}$ & $20 \mathrm{~kJ} / \mathrm{m}^{2}$ \\
\hline Ocular damage & Animals involved & Duration & Animals involved & Duration \\
\hline Ocular inflammation & $30 \%$ & day $4 \ldots 7$ & $100 \%$ & day $3 \ldots 7$ \\
\hline Cornea: superficial opacity & $50 \%$ & day $4 \ldots 7$ & $100 \%$ & day $4 \ldots 7$ \\
\hline diffuse opacity & no & & $70 \%$ & day 7 \\
\hline micro tumor & no & & $50 \%$ & from 4 weeks on \\
\hline neovascularization & $30 \%$ & from 4 weeks on & $70 \%$ & from 4 weeks on \\
\hline
\end{tabular}

Table 4.

$\mathrm{G}$ eneral summary of ocular damage other than to the lens after U V R ex posure; based on miscellaneous observations with the nak ed eye during the long-term ex periment (A ppendix I). 

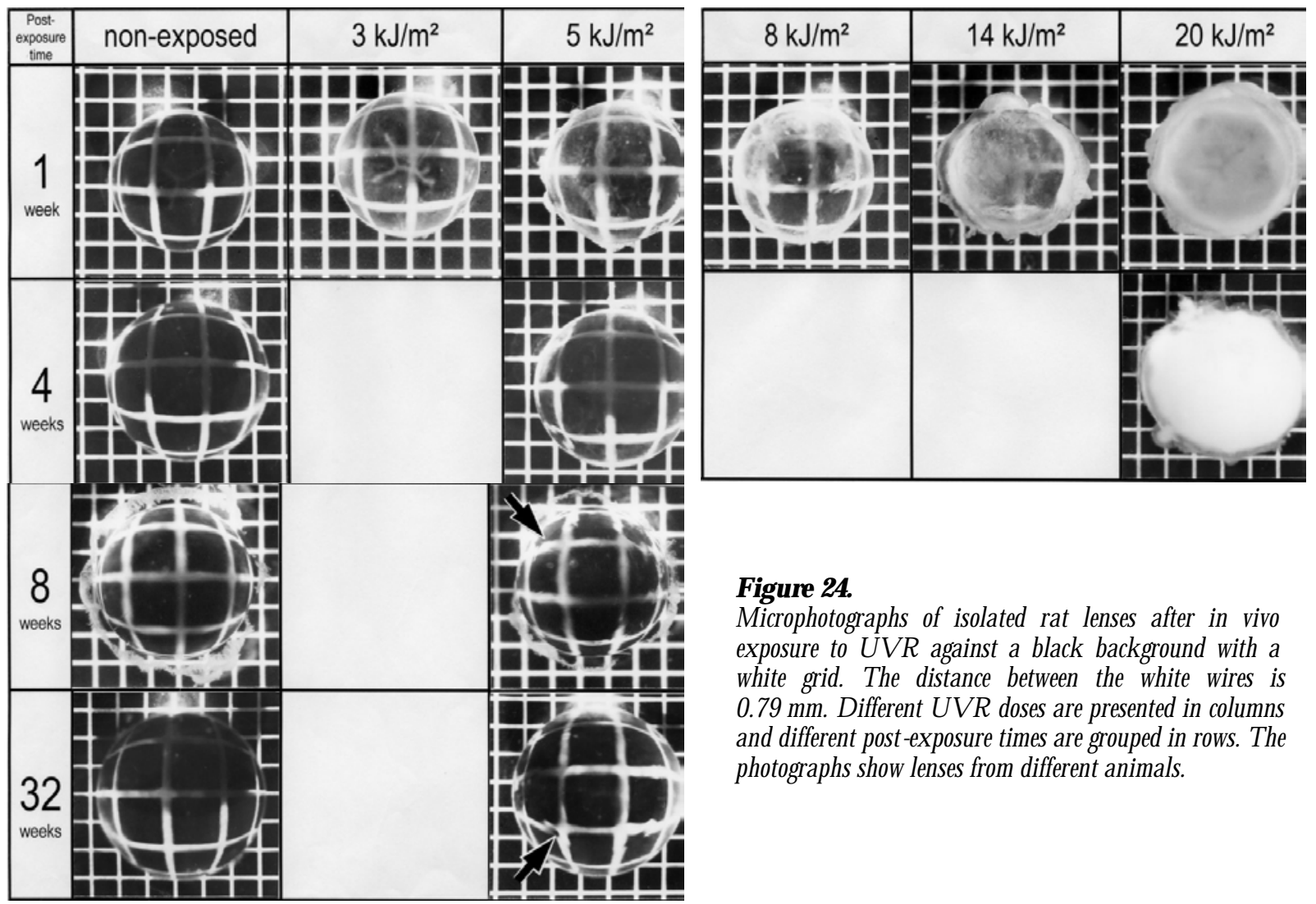

Figure 24.

Microphotographs of isolated rat lenses after in vivo exposure to UV R against a black background with a white grid. The distance between the white wires is $0.79 \mathrm{~mm}$. D ifferent UV R doses are presented in olumns and different post-ex posure times are grouped in rows. The photographs show lenses from different animals.

\begin{tabular}{ccccccc}
\hline \multirow{2}{*}{$\begin{array}{c}\text { Post- exposure time } \\
\text { (weeks) }\end{array}$} & \multicolumn{5}{c}{ Forward light scattering (tEDC) } \\
\cline { 2 - 6 } & non-exposed & 3 & 5 & UVR dose $\left(\mathrm{kJ} / \mathrm{m}^{2}\right)$ & 14 & 20 \\
\hline 1 & 0.126 & 0.185 & 0.311 & 0.347 & 0.703 & 1.030 \\
4 & 0.110 & & 0.163 & & & 0.634 \\
8 & no data & no data & & \\
32 & no data & no data & & \\
\hline
\end{tabular}

Table 5.

M easured forward light scattering in the lenses shown in figure 24.

After more extended post-exposure intervals $\left(5 \mathrm{~kJ} / \mathrm{m}^{2}\right.$ after 8 and 32 weeks) or higher doses $\left(8 \mathrm{~kJ} / \mathrm{m}^{2}\right)$, opacities are seen mainly in the equatorial region and less in the polar region of the exposed lens. This location of the opacities is more common in human cortical cataract (Figure 24).

The macroscopic appearance of lenses exposed to a high dose of UVR $\left(20 \mathrm{~kJ} / \mathrm{m}^{2}\right)$ illustrates the fact that after severe damage, the lens becomes so opaque that the forward light scattering decreases. This is due to attenuation of transmittance in the lens and is described in Appendix I Figure 24 and Table 5). Foo and Maclean (1996) were confronted with the same effect in human cataract. They mention that severe nuclear cataract can attenuate so much backscattered light that the lens appears less dense in retroillumination image analysis. 
In Appendix VI, the development of lens opacities was studied between $24 \mathrm{~h}$ and 8 weeks after a UVR exposure of $5 \mathrm{~kJ} / \mathrm{m}^{2}$. O ne day after UVR exposure, lenses had flaked confluent dots or small granules scattered over the anterior surface; the posterior surface looked normal. At 7 days post-exposure, the lens surface was rough and appeared corrugated and equatorial opacities were seen. The anterior side of the lens was more opaque than the posterior. Vacuoles were visible at the lens equator in the cortex. At 56 days post-exposure, the lens surface was clear again. However, a narrow equatorial cortical light scattering ring was visible. Because this light scattering ring was visible in coronal and sagittal view, it was assumed to have a shell shape (Appendix VI, Figure 2).

\subsubsection{Lens epithelium}

In vivo low dose UVR leads within one day to apoptosis and disintegration of the lens epithelium. After one week the epithelium contains extracellular spaces. Within several weeks after exposure, the lens epithelium recovers (Appendix V and VI).

Necrotic and apoptotic cells have different morphological features: necrotic cells show a dilated endoplasmatic reticulum, swollen mitochondria, ruptured plasma membrane, general cell swelling and groups of cells are affected. Apoptotic cells shrink, lose intercellular contact, undergo fragmentation into membrane bound segments with intact endoplasmatic reticulum, mitochondria, and lysosomes. Apoptosis usually effects individual cells which are then phagocytized by surrounding cells or macrophages (Kuszak 1997).

We consider apoptosis or programmed cell death as a cell response after low dose damage, and necrosis as response after high dose damage. After low dose damage, programmed cell death leaves a greater chance for tissue repair because cells with DNA damage are removed. After high dose damage, the tissue is destroyed by necrosis, with a lower chance for repair.
Andley and co-workers (1999) showed that photoproducts (cyclobutane pyrimidine dimers and (6-4) photoproducts) are eliminated within 1 to 2 days after UVR exposure, depending on UVR dose and type of photoproduct. They conclude that cells either repair DNA damage and proceed in the cell cycle or do not repair it and are eliminated by cell death.

The p53 protein is known to play a role in cell cycle regulation, induction of apoptosis and stabilization of the genome (Wilson 1999). In this way p53 is involved in controlling the cellular response to DNA damaging agents. Cells exposed to UVR raise their concentration of p53 protein. A high level of p53 blocks cell proliferation and prevents the cell from progressing into S phase and replicating DNA. The cells are either delayed in G1 phase or die by programmed cell death (Alberts 1994a).

\subsubsection{Lens fibers}

O ne week after low dose UVR exposure, equatorial parts of superficial lens fibers contain extracellular spaces (Appendix VI). The extracellular spaces together with locally disarranged fibers produce a corrugated opaque lens surface and equatorial opacities. Within several weeks after exposure, the lens epithelium recovers, and new fibers develop normally. The lens fibers regain normal water balance and fill up the extracellular spaces. Repair, however, is incomplete, and disarranged fibers remain in the cortex, producing a subtle shell-shaped opacity.

In this way, subtle damage to the lens fibers induced by UVR may accumulate during a lifetime and contribute to the formation of cortical cataract. Indeed, the main type of lens opacification found in the human is cortical cataract (Sasaki 1997) and the rate of opacification in the outer lens cortex is about 4-5 times higher than the nuclear onset of cataracts (Hockwin 1997). 
UVR exposure initially causes DNA damage in the lens epithelium which is repaired within a few days, either keeping the cells functioning properly or removing them by programmed cell death (Appendix VI). New epithelial cells proliferate and enable the epithelium to be completely repaired. $D$ amage to the lens fibers is delayed as compared to the epithelium and is restricted to the fibers differentiating at the moment of exposure. How both events, in epithelium and fibers, are linked remains a challenging question. UVR may reach the lens equator by multiple scattering and might damage differentiating fibers directly, or there may be signals from the injured and repairing epithelium which cause the damage of the lens fibers, or the disarranged epithelium may not be able to optimally regulate water and ion homeostasis.

\subsection{Reasons for light scattering (VI, VII)}

\subsubsection{Spatial order of lens fibers}

Light is always scattered in the crystalline lens, but a regular spatial order of the lens fibers causes destructive interference of the locally scattered light and hence less total light scattering (Bettelheim 1985, Hemenger 1988). Therefore, the spatial order of the lens fibers is crucial for lens transparency. This fiber order can be evaluated by Fourier image analysis. Before the time of computers which made the calculation of Fourier power spectra very fast, diffraction was used as optical Fourier analysis. Depending on the mathematic algorithm applied, computer Fourier calculations induce errors by rounding and optical Fourier analysis can give more reliable results. The pattern of the diffraction and Fourier peaks from a regular sample corresponds to the geometry and spacing in the sample.
Jose (1986) discussed the signals between the epithelium and the fibers after UVR exposure. If the lens epithelium is disrupted either in morphology or metabolism, its interaction with fibers in the bow may be altered. Also damage to the genome of the epithelial cells may affect the lens fibers, because cues for differentiation that normally pass from the epithelium to the fibers are lost. Consequently, the fibers fail to differentiate normally.

In contrast to epithelial cells, fiber cells do not contain thymidine, which is required for DNA synthesis. Therefore, damage in the fibers cannot be repaired via repair-replication of DNA (Modak 1972).

René Descartes (1596-1650), a French mathematician, scientist, and philosopher was the first to describe a corona due to diffraction by particles in the human eye (Figure 25). The theory of diffraction was not known at that time, but Descartes speculated that the cause of the corona should be in the eye that sees them (Simpson 1953). He published Figure 25 in his "Discours de la méthode" in 1637. In three essays forming part of the Discourse, he illustrated his method for utilizing reason in the search for truth in the sciences. In Dioptrics he then presented the law of refraction, in Meteorology he explained the rainbow, and in Geometry he gave an exposition of analytic geometry ("D escartes, René" Encyclopædia Britannica O nline).

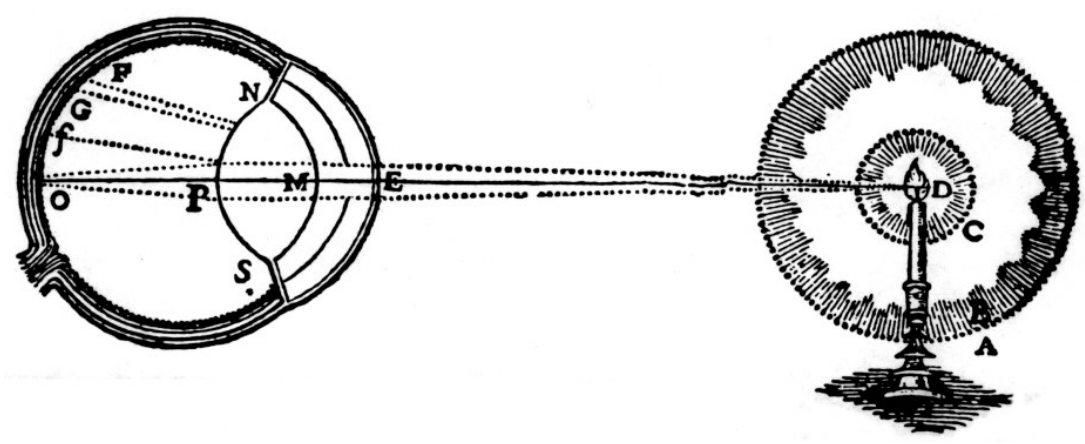

Figure 25.

A corona which D escartes observed around the flame of a candle and described in "D isours de la M éthode" (1637).

(Reprinted, with permission, from Simpson (Brit. J. O phthal. (1953) 37, 450-486). Copyright by BJM Publishing $\mathrm{G}$ roup, $\mathrm{L}$ ondon.) 
In a review on ocular halos and coronas, Simpson (1953) explained that Descartes' corona was due to particles on the anterior surface of the cornea. Another diffraction phenomenon seen by the human eye is the lenticular halo. In 1897, D ruault explained the lenticular halo due to the circular optical grating formed by the radial fibers at the periphery of the crystalline lens Figure 2 (D ruault 1898). In 1953, Simpson estimated the fiber width of his own crystalline lenses from the size of the lenticular halo that he could see (Simpson 1953).

Sir David Brewster was probably the first person who used an optical diffraction technique to estimate the fiber dimensions in animal lenses (Brewster 1816). Philipson (1973) showed a diffraction pattern from slices of cortical areas about $500 \mu \mathrm{m}$ thick from the human lens illuminated with a helium-neon laser Figure 26a). The peaks in his diffractogram corresponded to a spacing of $7 \mu \mathrm{m}$, most likely caused by the regular spacing of the lens fibers. However, there are only peaks distinguishable in one direction.

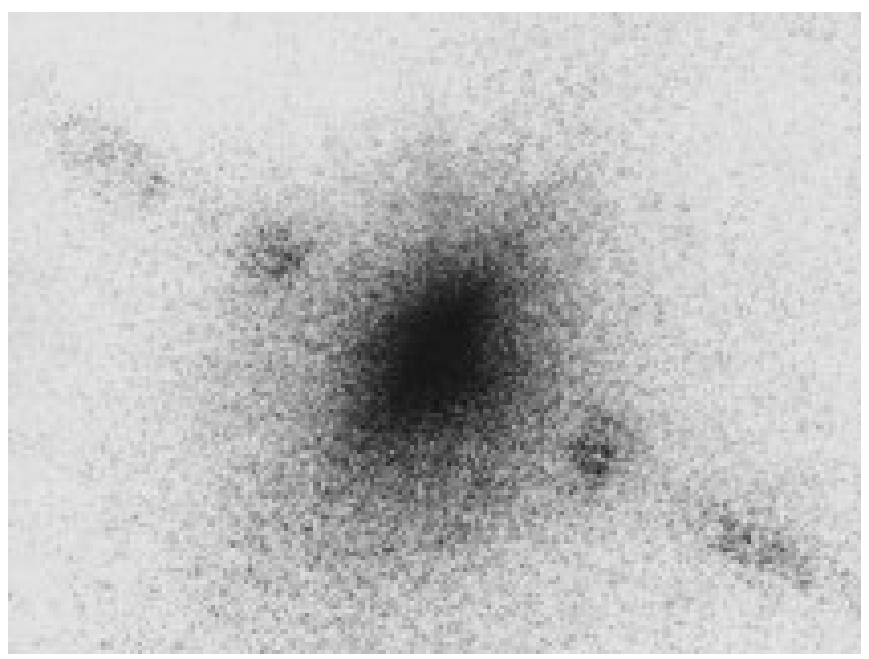

\section{Figure 26a.}

D iffractogram showing low angle laser light scattering from a section of human transparent lens cortex.

(Reprinted, with permission, from Philipson (1973). Copyright by A cademic Press, L ondon.)
This suggests that the lens smple only contained fibers in longitudinal section. A cross-section of the fibers would reveal peaks in two dimensions; fiber width and fiber thickness.

In Appendix VI, Fourier analysis was applied to describe the order of the lens fiber lattice. If there is a regular order in the lattice, the Fourier power spectrum reveals peaks which can be measured and the average fiber dimensions can be estimated. Beyond the scope of Appendix VI, I will give here an idea how changes in the lattice order can be quantitatively described.

From the areas marked in Figure 27, Fourier power spectra were calculated. Figure 26b gives an example of such a spectrum. Then, intensity profiles were calculated along a line from the center of the Fourier spectrum as indicated by the arrow in Figure 26b. Figure 28 shows these intensity profiles from the areas A, B and C as marked in Figure 27. Each diagram contains the intensity profile from the exposed and non-exposed lens.

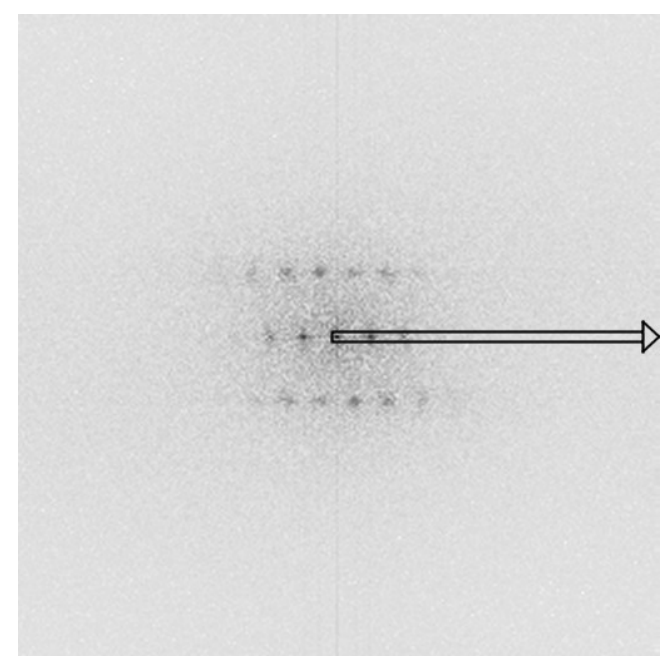

Figure 26b.

E x ample of $F$ ourier power spectrum. A rrow indicates area and direction of intensity profile measured. 
Figure 27.

Mid-coronary paraffin lens sections stained with wheat germ agglutinin. A reas of the Fourier transform mark ed.

(See A ppendix V I)

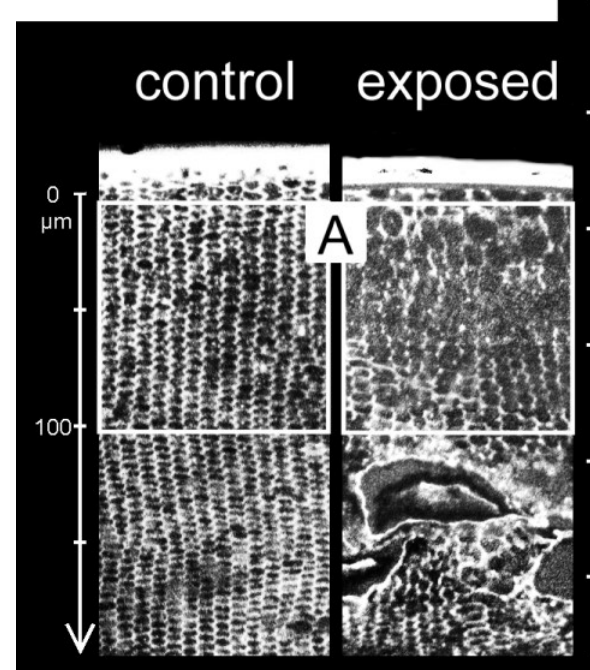

1 week after UVR

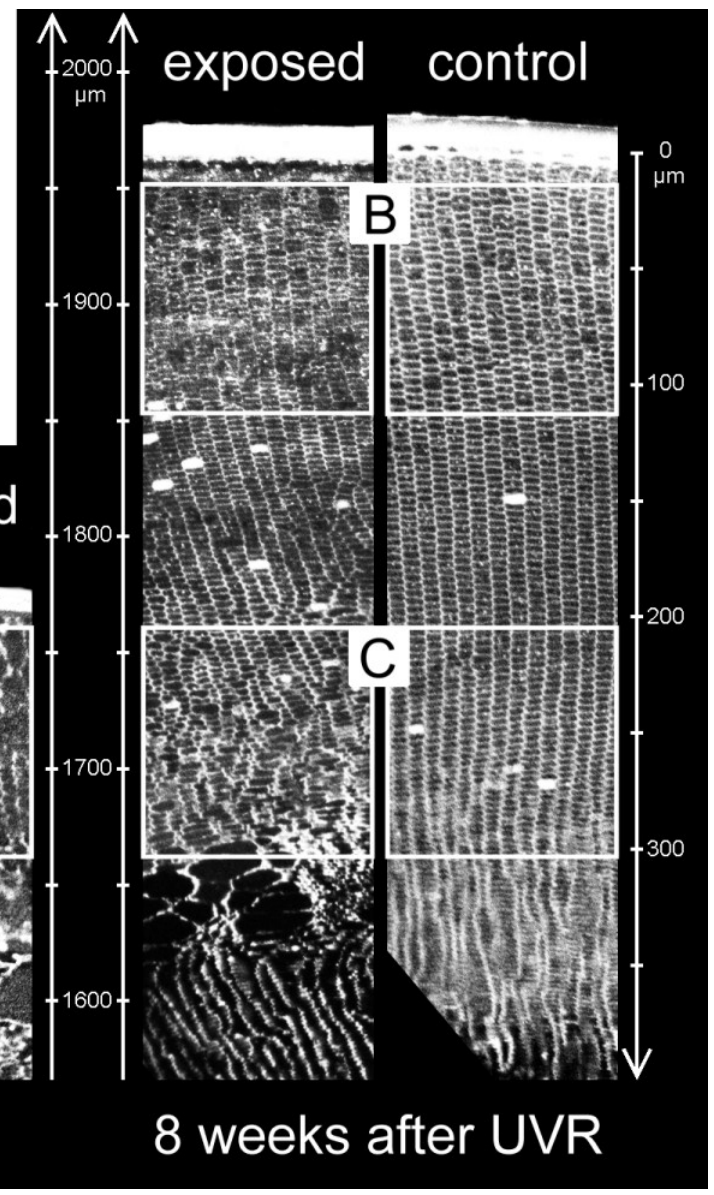

\section{Figure 28.}

Intensity profiles of $F$ ourier power spectra corresponding to the areas mark ed in figure 27.

Equivalent distance in spatial domain $(\mu \mathrm{m})$

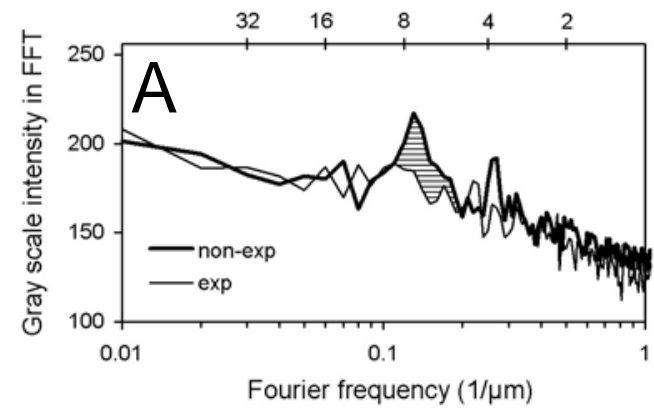

Equivalent distance in spatial domain $(\mu \mathrm{m})$
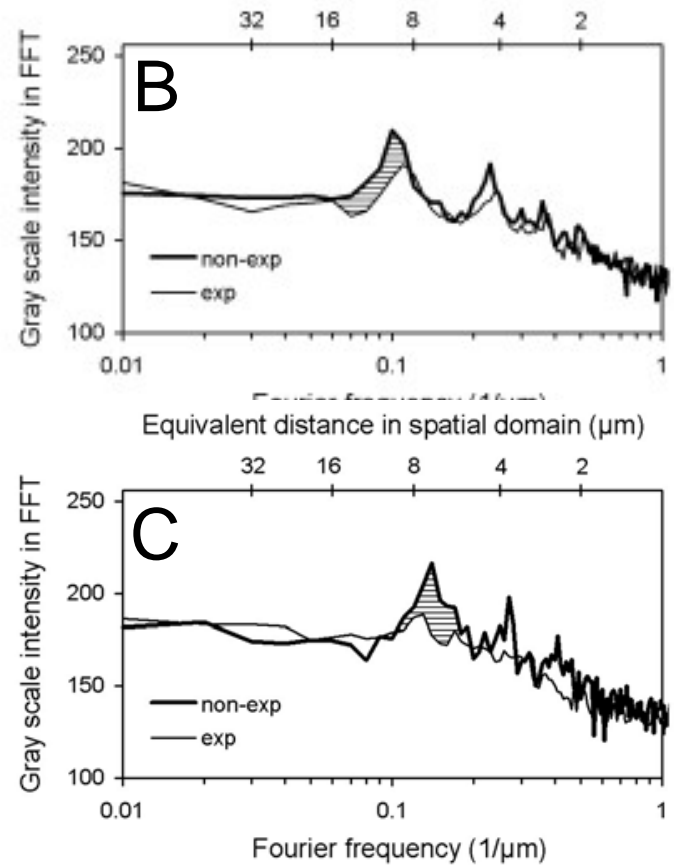
All profiles from non-exposed lenses show a peak (first harmonic maximum) which represents the average fiber width (at about $8 \mu \mathrm{m}$ ). High frequencies at the right side of the diagrams contain information about the fiber membrane thickness and the focal quality of the image.

The profiles from the damaged areas of exposed lenses ( $\mathrm{A}$ and $\mathrm{C}$ ) do not show clear peaks (Figure 28, Appendix VI, Fig. 5f). Therefore, an average fiber width cannot be estimated. However, a way of comparing the intensity profiles is to compare the areas under the curves (Taylor \& Costello 1999). Such a comparison is illustrated by the outlined area between the curves in Figure 28. Quantitative evaluation of the areas between the intensity profiles should consider Fourier frequencies between half and double frequency of the first harmonic maximum.

\subsubsection{Refractive index distribution}

The lens maintains a gradient of refractive index that allows it to produce an image without significant spherical and chromatical aberration (Clark 1994). In the lens, the refractive index is proportional to the protein concentration. A continuous increase of the protein concentration is established due to regulated protein synthesis and cell dehydration during cell differentiation.

At 6 months after a short-term low dose UVR exposure $\left(5 \mathrm{~kJ} / \mathrm{m}^{2}\right)$, local variations of the refractive index induced a subtle cortical light scattering (Appendix VII, Fig. 8). At the same time, no global change of the refractive index was found between exposed and non-exposed lenses. The local variations in protein density cancel each other out when averaged between the individuals because they are displaced somewhat along the lens radius and they have positive or negative magnitude. The absence of a significant difference of the protein density in the outer cortex, supports the earlier morphological finding (Appendix VI) that the new fibers that grow after the UVR exposure develop normally.
However, lenses exposed to UVR grow slower than their non-exposed contralaterals (Appendix VII, Fig. 6a and 6b). Even though UVR-induced light scattering has almost returned to normal several weeks after low dose exposure, there was a decrease in the mass of these lenses. The finding that both water content and dry mass decreased by about $10 \%$ after low dose exposure, shows that the average protein density is kept constant.

This shows how excellent is the capacity of the lens for repair. Despite the fact that the UVR exposure causes a slower growth of the lens, the average protein concentration is kept constant. Also the protein distribution in the fiber layers developed after the exposure recovers to normal. In this way, the complex repair processes maintain the optical function of the lens.

\subsubsection{Lens transparency theory}

Loss of transparency in a medium can be caused by absorption and scattering. In cataract, absorption plays a minor role (Benedek 1971, Philipson 1969a, b). There are mainly two types of potential scattering centers in the lens: the proteins in the fiber cytoplasm and the fiber membranes. Proteins give rise to small particle scattering $(d<\lambda / 5)$ and fiber membranes to large particle scattering $(d>5 \lambda)$ (Trokel 1962).

However, the lens is not an opaque tissue, even though proteins and fiber membranes scatter light. Neither, proteins nor fiber membranes scatter indepently of their neighbors. Correlation in the position reduces the scattering (Trokel 1962). In other words, a high degree of spatial order leads to a transparent tissue.

Why high spatial order leads to transparency, can be explained by interference theory (Benedek 1971, Trokel 1962). Light incident to the lens is reflected and diffracted at proteins and fiber membranes. If proteins and fibers have a regular spaing, the reflected or diffracted light is in phase and the light waves cancel each other out in directions other then the incident light path (destructive interference). As a result, the light is transmitted through the lens along the incident light path. 
If protein and fibers have an irregular spading or random variations in their distribution, the reflected or diffracted light is out of phase and the waves do not cancel each other out in directions other then the incident light path (onstrudive interferenoe). Behind the lens, this results in light scattering out of the incident light path.

Therefore, regular spatial fluctuations decrease light scattering because of destructive interference. Examples for regular spatial fluctuations are the lens fiber lattice in normal lenses (Appendix VI, Fig. 5 and Figure 27) and the smooth increase of the refractive index in normal lenses (Appendix VII, Fig. 8).
In contrast, random spatial flucuations cause light scattering because of constructive interference. Examples for random spatial fluctuations are the disturbed fiber order in UVR exposed lenses (Appendix VI, Fig. 5 and Figure 27) and the local variations in the refractive index after exposure (Appendix VII, Fig. 8).

The spatial distribution important for the optical properties of the lens is described by the refractive index. All spatial fluctuation, of proteins or fiber membranes, result in fluctuations of the refractive index. Therefore, the transparency of the lens depends on the smooth and gradual distribution of the refractive index. 


\section{CONCLUSIONS}

$\square \quad$ Building on earlier observations, the current findings indicate that the optimal time to detect low dose UVR-induced cataract is one week after exposure.

The dose-response function for UVR-induced cataract is continuous and has a sigmoid shape. The intensity of forward light scattering in the rat lens increases exponentially with increasing UVR dose between 0.1 and $14 \mathrm{~kJ} / \mathrm{m}^{2}$ and starts to flatten at around $20 \mathrm{~kJ} / \mathrm{m}^{2}$.

A method for experimental estimation of toxicity, for continuous dose response relationships was developed. First, a lower limit of pathological light scattering is defined from the frequency distribution of light scattering of normal clinically clear lenses. Then, the intersection of this limit with the dose-response function gives a dose which is defined as the "maximum acceptable dose" or MAD .

$\square \quad$ Two UVR exposures with a 0 or $6 \mathrm{~h}$ interval produce the same degree of lens opacification. When the second exposure follows 24 or $48 \mathrm{~h}$ after the first, lenticular damage increases. Repair processes between 24 and $48 \mathrm{~h}$ after exposure appear to be sensitive to UVR, and an additional exposure during this time may aggravate cataract development.

A UVR dose of twice the maximum acceptable dose induces programmed cell death which peaks $24 \mathrm{~h}$ post-exposure and involves the entire epithelium. D ead cells are removed from the epithelium by phagocytosis.

A UVR dose of twice the maximum acceptable dose causes cataract which is largely repairable. Extracellular spaces develop in the epithelium and fibers. Within several weeks after exposure, the epithelium recovers and new morphologically normal fibers develop. The originally affected fibers are repaired. However, this repair is incomplete, leaving a small zone of enhanced light scattering in the equatorial cortex.

$\square \quad$ At 6 months after twice the maximum acceptable UVR dose, no global change of the refractive index was found. However, local variations of the refractive index induced a subtle cortical light scattering. 


\section{ACKNOWLEDGMENT}

My sincere appreciation goes to my main tutor Prof. Per G. Söderberg for his encouragement and confidence, for his never-failing support, for the many fruitful discussions, and his constructive criticism of my work.

My sincere gratitude goes to D ocent Enping Chen and my colleague Stefan Löfgren for introducing me to biomedical techniques and for sharing their medical knowledge, and to Prof. Bo Lindström for expanding my knowledge in statistics. My thanks is extended to my colleague Marcelo Ayala for many interesting discussions and help in the daily work.

Grateful acknowledgment is made for the skilled work of Peter Goldman in manufacturing experimental equipment, to Maud Leindahl, for prompt help with her excellent photographic work, and to Claire Johansson, Charlotte Ovesen and Britt-Marie Karlheden for their help and support with administrative work at all times.

My sincere thanks goes to my tutors in Amsterdam, Prof. Gijs F. J. M. Vrensen and Jan van Marle and to Ben Willekens and Anneke de Wolf for their generous help with electron microscopy.

Acknowledgment is made to Hjalmar Brismar at the Karolinska Hospital for his help with laser scanning microscopy.

My sincere thanks goes to Agneta Bonnevier, Margareta Oskarsson and Berit Spångberg for excellent help with histologic preparations and to Ylva Lagerquist and Calle Oskarson for their help with image processing. Ithank John Merriam for many interesting discussions and for his English language checks.

My thanks goes also to Ann Germann at Solfjädem $O$ ffset $A B$ and to Priska Baumgartl from the publisher Karger AG for their help and excellent cooperation, and to Janet Holmén for helpful linguistic comments.
Additionally, my thanks to Monica Aronsson, Ann Hagström and Ann Almström at the animal departments at St. Erik's and at the Department of Physiology and Pharmacology of the Karolinska Institute.

My thanks is extended to friends and colleagues at the Research department of St. Erik's Eye Hospital for their kind help and friendship.

Last but not least, I would like to thank Avocado, O range, Mango and Brain who did most of the routine data and word processing and helped with fast communication.

Significant financial contributions were made by:

$\square \quad$ Gottlieb Daimler - und Karl Benz - Stiftung

$\square \quad$ Stiftelsen för Ögonforskning i Stockholm

$\square \quad$ ELFAs Forskningsstiftelse

$\square \quad$ Anders Otto Swärds Stiftelse

$\square \quad$ Hildur Petterssons Stiftelse

$\square \quad$ Karolinska Institutets Resebidragsstiftelser

$\square \quad$ Karolinska Institutets Fonder

$\square \quad$ Carmen and Bertil Regnérs Stiftelse

$\square \quad$ Swedish Society of Medicine

$\square \quad$ Swedish Society for Medical Research

$\square \quad$ Clas Groschinskys Minnesfond

$\square \quad$ Erik och Edit Fernströms Stiftelse

$\square$ Kronprinsessan Margaretas Arbetsnämnd för Synskadade

$\square \quad$ Swedish Radiation Protection Institute 


\section{BIBLIOGRAPHY}

ACG IH. 1995-1996 Threshold Limit Values for chemical substances and physical agents and Biological Exposure Indices. Cincinnati: American Conference of G overnmental Industrial Hygienists, 1996.

Adamsons I, Munoz B, Enger C, Taylor HR. Prevalence of lens opacities in surgical and general populations. A rch 0 phthalmol. 1991;109:993-7.

Alberts B, Bray D, Lewis J, Raff M, Roberts K, Watson JD . Chapter 6: Basic genetic mechanisms. M olecular biology of the cll. New York: Garland Publishing, 1994a:225-49.

Alberts B, Bray D, Lewis J, Raff M, Roberts K, Watson JD. Chapter 17: The cell-division cycle. M oleaular biology of the call. New Y ork: Garland Publishing, 1994b:863-7.

Andley UP, Fritz C, Morrison AR, Becker B. The role of prostaglandins $\mathrm{E} 2$ and $\mathrm{F} 2$ alpha in ultraviolet radiation-induced cortical cataracts in vivo. Invest 0 phthalmol $\mathrm{V}$ is Sa. 1996;37:1539-48.

Andley UP, Lewis RM, Reddan JR, Kochevar IE. Action spectrum for cytotoxicity in the UVA- and UVB-wavelength region in cultured lens epithelial cells. Invest 0 phthalmol $\mathrm{V}$ is Sci. 1994;35:367-73.

Andley UP, Song Z, Mitchell DL. DNA repair and survival in human lens epithelial cells with extended lifespan. C urr E ye Res. 1999;18:224-30.

Andley UP, Walsh A, Kochevar IE, Reddan JR. Effect of ultraviolet-B radiation on protein synthesis in cultured lens epithelial cells. Curr E ye Res. 1990;9:1099-106.

Andley UP, Weber JG. Ultraviolet action spectra for photobiological effects in cultured human lens epithelial cells. Photochem Photobiol. 1995;62:840-6.

Ayala M, Michael R, Löfgren S, Söderberg PG. Influence of exposure time for ultraviolet radiation induced cataract. ARVO abstract. Invest O phthalmol V is Sai. 1999;40:S528.

Ayala M, Michael R, Söderberg PG. In vivo cataract after repeated exposure to ultraviolet radiation. Exp E ye Res. 2000; in press.
Bachem A. O phthalmic ultraviolet action spectra. A m J 0 phthalmol. 1956;41:969-75.

Barer R, Joseph S. Refractometry of living cells. Q J Microsc Sá. 1954;95:399-423.

Behar-Cohen FF, Savoldelli M, Parel JM, Goureau $O$, Thillaye-G oldenberg $B$, Courtois $Y$, et al. Reduction of corneal edema in endotoxin-induced uveitis after application of L-NAME as nitric oxide synthase inhibitor in rats by iontophoresis. Invest 0 phthalmol V is Sa. 1998;39:897-904.

Benedek GB. Theory of transparency of the eye. A ppl 0pt. 1971;10:459-73.

Bener P. Appropriate values of intensity of natural UV radiation for different amounts of atmospheric ozone. Final Tech. Report., Contract DAJA37-68-C-1017. London: European Research Office, US Army, 1972.

Bettelheim FA. Physical basis of lens transparency. In: Maisel $\mathrm{H}$, editor. The ocular lens, structure, function and pathology. New Y ork: Marcel D ekker Inc., 1985:265-95.

Bochow TW, West SK, Azar A, Munoz B, Sommer A, Taylor HR. Ultraviolet light exposure and risk of posterior subcapsular cataracts. A rch 0 phthalmol. 1989;107:369-72.

Boettner EA, Wolter JR. Transmission of ocular media. Invest 0 phthalmol. 1962;1:776-83.

Breadsell RO, Wegener A, Breipohl W. UV-B radiation-induced cataract in the royal collage of surgeons rat. Ophthalmic Res. 1994;26:84-9.

Brewster D. On the anatomical structure of the crystalline lenses of animals, particulary that of the cod. Philos Trans R Soc L ond B Biol Sa. 1816;123:323-32.

Brilliant LB, Grasselt NC, Pokhrel RS, Kolstad A, Lepkowski JM, Brilliant GE, et al. Association among cataract prevalence, sunlight hours and altitude in the Himalayas. A m J E pidemiol. 1983;118:250-64.

Brismar H, Patwardhan A, Jaremko G, Nyengaard $\mathrm{J}$. Thickness estimation of fluorescent sections using a CSLM. J M icrosc. 1996;184:106-16. 
Brown VK. Acute toxicology in theory and practice. Chichester: John Wiley \& Sons, 1980.

Brücke E. Ueber das Verhalten der optischen Medien des Auges gegen Licht- und Wärmestrahlen. In: Müller J, editor. A rchiv fü A natomie, Physiologie und wissenschaftliche M edizin. Berlin: Verlag von Veit et comp, 1845:262-76.

Bunsen R, Roscoe H. Photochemische Untersuchungen. A nnalen der Physik und Chemie. 1862;117:529-62.

Carlsson B, Sjostrand J. Increased incidence of cataract extractions in women above 70 years of age. A population based study. A da O phthalmol Scand. 1996;74:64-8.

Chaudhuri A, Hallett PE, Parker JA. Aspheric curvatures, refractive indices and chromatic aberration for the rat eye. V ision Res. 1983;23:1351-63.

CIE Research Note. A reference action spectrum for ultraviolet induced erythema in human skin. CIE -Journal. 1987;6:17-22.

Clark JI. Principles and practice of ophthalmology. Philadelphia: W. B. Saunders, 1994.

Coroneo MT, Muller-Stolzenburg NW, Ho A. Peripheral light focusing by the anterior eye and the ophthalmohelioses. 0 phthalmic Surg. 1991;22:705-11.

Cruickshanks KJ, Klein BE, Klein R. Ultraviolet light exposure and lens opacities: the Beaver D am Eye Study. A m J Public $\mathrm{H}$ ealth. 1992;82:1658-62.

Davson H, Graham LT. The eye. New York: Academic Press, 1974.

DeChardonnet M. Sur la pénétration des radiations actiniques dans l'oeil de l'homme et des animaux vertébrés, et sur la vison des radiations ultra-violettes. Journal de physique theorique et appliquee. 1883;II. t. II:219-25.

D hir MD, D etels R, Alexander ER. The role of environmental factors in cataract, pterygium and trachoma. A m J 0 phthalmol. 1967;64:128-35.

Diffey BL. The calculation of the spectral distribution of natural ultraviolet radiation under clear day conditions. Phys M ed Biol. 1977;22:309-16.
Dillon J, Zheng L, Merriam JC, G aillard ER. The optical properties of the anterior segment of the eye: Implications for cortical cataract. E xp E ye Res. 1999;68:785-95.

D obson G. Exploring the atmoshere. Chapter 6: O zone in the atmosphere. Oxford: Claredon Press, 1963.

D olin PJ. Ultraviolet radiation and cataract: a review of the epidemiological evidence. $\mathrm{Br} \mathrm{J}$ O phthalmol. 1994;78:478-82.

D ruault A. Sur la production des anneaux colorés autour des flammes. A rchives of 0 phtalmology. 1898;18:312-21.

Duke-Elder S, MacFaul PA. Radiational injuries. In: Duke-Elder S, editor. System of ophthalmology, $\mathrm{V}$ ol. X IV Injuries, Part $2 \mathrm{~N}$ on-mechanical injuries. London: Henry Kimpton, 1972:91233.

Fagerholm PP, Philipson BT, Lindström B. Normal human lens - the distribution of protein. E xp E ye Res. 1981;33:615-20.

Finney DJ. Probit analysis. Cambridge, UK: Cambridge University Press, 1971.

Foo KPY, Maclean H. Measured changes in cataract over six months - sensitivity of the Nidek EAS-1000. 0 phthalmic Res. 1996;28:32-6.

Förster W, Busse H. Auswirkung ultravioletter Strahlung auf das Auge. A ugenärztliche Fortbildung. 1991;14:208-12.

G ates D M. Spectral distribution of solar radiation at the earth's surface. Scieno. 1966;151:523-9.

Hemenger RP. Small-angle intraocular light scatter: a hypothesis conceming its source. J O pt Soc A m [A ]. 1988;5:577-82.

Herman JR, Krotkov N, Celarier E, Larko D, Labow $\mathrm{G}$. The distribution of UV radiation at the earth's surface from TOMS measured UV-backscattered radiances. J G eophys Res A tmos. 1999;104:12059-76.

Hess C. VII. Inter. O phth. Kongress Heidelberg. 1868.

Hightower KR. A review of the evidence that ultraviolet irradiation is a risk factor in cataractogenesis. [Review]. D oc 0 phthalmol. 1994;3-4:205-20.

Hightower KR. The rule of the lens epithelium in development of UV cataract. [Review]. C urr E ye Res. 1995;14:71-8. 
Hightower KR, Reddan JR, McCready JP, Dziedzic DC. Lens epithelium: a primary target of UVB irradiation. E xp E ye Res. 1994;59:55764.

Hightower K, McCready J. Comparative effect of UVA and UVB on cultured rabbit lens. Photochem Photobiol. 1993;58:827-30.

Hockwin O. Multifactorial pathogenesis of "Senile Cataract". In: Glaesser G, Hockwin O, Vrensen GFJM, editors. E ye lens epithelium: $D$ amaging $M$ echanisms and L ens Transparency. Halle: Nova Acta Leopoldina NF 75, Nr. 299, 1997:37-44.

Hyman JW. The light book. Los Angeles: Jeremy P. Tarcher, 1990.

Johnson FS, Mo T, Green AES. Average latitudinal variation in ultraviolet radiation at the earth's surface. Photochem Photobiol. 1976;23:179-88.

Jose JG. The role of DNA damage, its repair and misrepair in the etiology of cataract: a review. O phthalmic Res. 1978;10:52-62.

Jose JG. Posterior cataract induced by UV-B radiation in albino mice. Exp E ye Res. 1986;42:11-20.

Jose JG, Pitts DG. Wavelength dependency of cataracts in albino mice following chronic exposure. E xp E ye Res. 1985;41:545-63.

Kistler J, Bullivant S. Structural and molecular biology of the eye lens membranes. [Review]. Crit Rev Biochem Mol Biol. 1989;24:151-81.

Klein BE, Klein R, Linton KL. Prevalence of age related lens opacities in a population. The Beaver D am Eye Study. O phthalmology. 1992;99:546-52.

Kuszak JR. A re-examination of primate lens epithelial cell size, density and structure as a function of development, growth and age. In: G laesser G, Hockwin O, Vrensen GFJM, editors. E ye lens epithelium: D amaging Mechanisms and L ens T ransparency. Halle: Nova Acta Leopoldina NF 75, Nr. 299, 1997:45-66.

Lerman S. Human ultraviolet radiation cataracts. Ophthalmic Res. 1980;12:303-14.

Lerman S. Biophysical aspects of comeal and lenticular transparency. C urr E ye Res. 1984;3:3-14.
Li HF, Petroll WM, Moller-Pedersen T, Maurer JK, Cavanagh HD, Jester JV. Epithelial and corneal thickness measurements by in vivo confocal microscopy through focusing (CMTF). Curr E ye Res. 1997;16:214-21.

Lindström B. Roentgen absorption spectrophotometry in quantitative cytochemistry, Thesis. A cta Radiol Suppl. 1955;125:All.

Löfgren S, Michael R, Söderberg PG . Age dependent development of ultraviolet radiation-induced cataract. JERMOV abstract. 0 phthalmic Res. 1997;29:144.

McCarty CA, Taylor HR. Light damage in cataract. Invest O phthalmol V is Sá. 1996;37:1720-3.

Merriam J. The concentration of light in the human lens. Trans A m 0 phthalmol Soc. 1996;XCIV:803-918.

Moan J, Dahlback A. The relationship between skin cancers, solar radiation and ozone depletion. Br J Cancer. 1992;65:916-21.

Modak SP. A model for transcriptional control in terminally differentiating lens fiber cells. In: Harris R, Allin P, Viza D, editors. Cell $D$ ifferentiation. The Prooedings of the First International C onference on C ell D ifferentiation. Copenhagen: Munksgaard, 1972:339-42.

Müller-Breitenkamp U, Hockwin O, Siekmann $H$, D ragomirescu $\mathrm{V}$. Ultraviolet radiation as cataract risk factor - A case report. D ev Ophthalmol. 1997;27:76-80.

Müller-Breitenkamp U, O hrloff C, Hockwin O. Aspekte zur Physiologie, Pathologie und Epidemiologie der Katarakt. O phthalmologe. 1992;89:257-67.

Munakata N. Continual increase in biologically effective dose of solar UV radiation determined by spore dosimetry from 1980 to 1993 in Tokyo. J Photochem Photobiol B. 1995;31:63-8.

Nolan CV, Amanatidis GT. European Commission research on the fluxes and effects of environmental UVB radiation. J Photochem Photobiol B. 1995;31:3-7.

Philipson BT, Fagerholm PP. Human subcapsular cataract - distribution of protein in relation to opacification. E xp E ye Res. 1981;33:62130. 
Philipson B. Light scattering in lenses with experimental cataract. A cta 0 phthalmol (C openh). 1969a;47:1-13.

Philipson B. Biophysical studies on normal and cataractous rat lenses. A cta 0 phthalmol Suppl. 1969b;103:5-28.

Philipson B. Distribution of protein within the normal rat lens. Invest 0 phthalmol. 1969c;8:258-70.

Philipson B. Changes in the lens related to the reduction of transparency. Exp E ye Res. 1973;16:29-39.

Phillips R. Sources and application of ultraviolet radiation. London: Academic Press, 1983.

Pitts DG. Calculation methods for ocular protection. In: Pitts D G, Kleinstein RN, editors. E nvironmental vision. Interadions of the eye, vision, and the environment. Boston: Butterworth-Heinemann, 1993:262-6.

Pitts DG, Cullen AP, Hacker PD. O cular effects of ultraviolet radiation from 295 to $365 \mathrm{~nm}$. Invest O phthalmol V is Sai. 1977;16:932-9.

Remtulla S, Hallett PE. A schematic eye for the mouse, and comparisons with the rat. $\mathrm{V}$ ision Res. 1985;25:21-31.

Rosenthal FS, Bakalian AE, Lou CQ, Taylor HR. The effect of sunglasses on ocular exposure to ultraviolet radiation. A m J Public $\mathrm{H}$ ealth. 1988a;78:72-4.

Rosenthal FS, Phoon C, Bakalian AE. The ocular dose of ultraviolet radiation to outdoor workers. Invest 0 phthalmol $V$ is Sa. 1988b;29:649-56.

Sallman L. Experimental studies on early lens changes after roentgen irradiation. A rch O phthalmol. 1952;47:305-20.

Sandvig KU, Kravik K, Haaskjold E, Blika S. Epithelial wound healing of the rat cornea after excimer laser ablation. A da 0 phthalmol (Copenh). 1997;75:115-9.

Sasaki K. Epidemiology - Search for risk factors of cataract formation. In: G laesser $\mathrm{G}$, Hockwin O, Vrensen GFJM, editors. E ye lens epithelium: D amaging M echanisms and L ens Transparency. Halle: Nova Acta Leopoldina NF 75, Nr. 299, 1997:25-36.

Schein OD, West S, Munoz B, Vitale S, Maguire M, Taylor HR, et al. Cortical lenticular opacification: distribution and location in a longitudinal study. Invest 0 phthalmol V is Sa. 1994;35:363-6.

Schmidt J, Schmitt C, Wegener A. Experimenteller Beitrag zur linsenschädigenden Wirkung ultravioletter Strahlung. Fortschr 0 phthalmol. 1988;85:689-94.

Schmitt C. Tierexperimentelle Untersuchungen früher Veränderungen der Augenlinse nach Röntgen- und UV-A-Bestrahlung. Dissertation. Bonn: Friedrich-WilhelmsUniversität, 1988.

Shindo Y, Hashimoto T. Time course of changes in antioxidant enzymes in human skin fibroblasts after UVA irradiation. J D ermatol Sa. 1997;14:225-32.

Simpson GC. O cular halos and coronas. Br J 0 phthalmol. 1953;37:450-86.

Sliney D H. Physical factors in cataractogenesis: Ambient ultraviolet radiation and temperature. Invest 0 phthalmol $\mathrm{V}$ is Sad. 1986;27:781-90.

Sliney DH. UV radiation ocular exposure dosimetry. J Photochem Photobiol B. 1995;31:69-77.

Sliney DH, Wolbarsht ML. Safety standards and measurement techniques for high intensity light sources. V ision Res. 1980a;20:1133-41.

Sliney D, Wolbarsht M. Safety with lasers and other optical sources. New York: Plenum Press, $1980 \mathrm{~b}$.

Smith AH, Waxweiler RJ, Tyroler HA. Epidemiologic investigation of occupational carcinogenesis using a serially additive expected dose model. A m J E pidemiol. 1980;112:787-97.

Söderberg PG. Acute cataract in the rat after exposure to radiation in the $300 \mathrm{~nm}$ wavelength region. A study of the macro-, micro- and ultrastructure. A da 0 phthalmol (Copenh). 1988;66:141-52.

Söderberg PG. Mass alteration in the lens after exposure to radiation in the $300 \mathrm{~nm}$ wavelength region. A da 0 phthalmol (Copenh). 1989;67:633-44.

Söderberg PG . Experimental cataract induced by ultraviolet radiation. A da 0 phthalmol (Copenh). 1990a;68:1-77. 
Söderberg PG. D evelopment of light dissemination in the rat lens after exposure to radiation in the $300 \mathrm{~nm}$ wavelength region. 0 phthalmic Res. 1990b;22:271-9.

Söderberg PG, Chen E, Lindström B. Determination of $\mathrm{Na}$ and $\mathrm{K}$ in the rat lens by atomic absorption spectrophotometry. A da 0 phthalmol (C openh). 1989;67:582-92.

Söderberg PG, Chen E, Lindström B. An objective and rapid method for the determination of light dissemination in the lens. A da Ophthalmol (C openh). 1990;68:44-52.

Söderberg PG , Löfgren S. Ultraviolet radiation cataract, dose dependence. SPIE . 1994;2134B:92-8.

Söderberg PG, Löfgren S, Michael R, GonzalezCirre X. New method for measurement of in vivo penetration of UVR into the crystalline lens. SPIE . 1998;3246:43-7.

Söderberg PG, Rol P, Parel J. Ultraviolet radiation transmittance of the lens capsule. Poster presentation. Association for Research in Vision and Ophthalmology 1996. Ft. Lauderdale, USA. Invest O phthalmol V is Sad. 1996;37:S755.

Spector A. O xidative stress-induced cataract: mechanism of action. [Review]. FA SE B J. 1995;9:1173-82.

Stevens MA, Bergmanson JPG. D oes sunlight cause premature aging of the crystalline lens? J A m Optom A ssoc. 1989;60:660-3.

Stuart DD, Cullen AP, Sivak JG , D oughty MJ. Optical effects of UV-A and UV-B radiation on the cultured bovine lens. $\mathrm{C}$ urr E ye Res. 1994;13:371-6.

Stuart DD , D oughty MJ. In vitro UVB irradiation of bovine crystalline lens causes damage and reduction in leucine aminopeptidase activity in lens epithelium. J Photochem Photobiol B. 1995;32:81-7.

Sydenham MM. The measurement of ultraviolet radiation at the surface of the eye. $\mathrm{PhD}$ thesis. Brisbane: Queensland University of Technology, 1995.

Taylor HR. Ultraviolet radiation and the eye: an epidemiologic study. T rans A m 0 phthalmol Soc. 1990;87:802-53.
Taylor HR, West SK, Rosenthal FS, Munoz B, Newland HS, Abbey $H$, et al. Effect of ultraviolet radiation on cataract formation. N E ngl J M ed. 1988;319:1429-33.

Taylor VL, Costello MJ. Fourier analysis of textural variations in human normal and cataractous lens nuclear fiber cell cytoplasm. E xp E ye Res. 1999;69:163-74.

Trokel S. The physical basis for transparency of the crystalline lens. Invest 0 phthalmol. 1962;1:493501.

Tuffs A. Die Wirkung von ultravioletter Strahlung auf die Augenlinse. Entwicklung eines Kataraktmodells und Testung der Antikataraktogenen Wirkung von BendazacL-Lysin Salz. Dissertation. Bonn: FriedrichWilhelms-Universität, 1991.

van der Leun JC. UV radiation from sunlight: summary, conclusions and recommendations. J Photochem Photobiol B. 1996;35:237-44.

van Heyningen R. What Happens to the Human Lens in Cataract. Sa A m. 1975;233:70-81.

van Leeuwenhoek A. The collected letters of Antoni van Leeuwnhoek. Vol. I. Amsterdam: Swets \& Zeitlinger, 1939.

van Leeuwenhoek A. The collected letters of Antoni van Leeuwnhoek. Vol. IV. Amsterdam: Swets \& Zeitlinger, 1952.

Verhoeff FH, Bell L, Walker CB. The pathological effects of radiant energy upon the eye. Proc A m A cad A rt Sá. 1915/ 16;51:629-818.

Waynforth HB, Flecknell PA. Experimental and surgical techniques in the rat. London: Academic Press, 1992.

Wegener AR. In vivo studies on the effect of UVradiation on the eye lens in animals. D oc 0 phthalmol. 1994;3-4:221-32.

West SK, Duncan DD, Munoz B, Rubin GS, Fried LP, Bandeen-Roche K, et al. Sunlight exposure and risk of lens opacities in a population-based study: the Salisbury Eye Evaluation project. JA M A . 1998;280:714-8.

Wester U. Solar ultraviolet radiation on the canary islands and in Sweden - a comparison of irradiance levels. In: Paschier W, editor. H uman ex posure to UV R. Amsterdam: Elsevier Science Publishers, 1987:275-9. 
Wester U. UV-exposure and ozone monitoring with a dual bandpass solar UVA-UVB meter in Stockholm since 1989. In: Shima A, editor. F rontiers of photobiology. Amsterdam: Elsevier Science Publishers, 1993:519-22.

Wester U. Personal information. Stockholm: Swedish Radiation Protection Institute, 1996.

Widmark J. Ueber den Einfluss des Lichtes auf die vorderen Medien des Auges. Skand A rch f Physiol. 1889;1:265-330.

Widmark J. Ueber die D urchlässigkeit der Augenmedien für ultraviolette Strahlen. Beiträge zur 0 phthalmologie. Stockholm: 1891:460-502.

Widmark J. Über den Einfluss des Lichtes auf die Linse. In: Widmark J, editor. Mitteilungen aus der A ugenk link des Carolinischen M ediooChirugischen Instituts zu Stodk holm. Jena: Verlag von Gustav Fischer, 1901:135-49.

Wilson SE. Stimulus-specific and cell type-specific cascades: emerging principles relating to control of apoptosis in the eye. Exp E ye Res. 1999;69:255-66.

Wurtman RJ. The effect of light on the human body. Sa A m. 1975;233:68-77.
Zar JH. Chapter 6.3. The distribution of means. In: Zar JH, editor. Biostatistical analysis. Upper Saddle River, NJ: Prentice-Hall International, 1999a:76-9.

Zar JH. Chapter 8.4. Power and sample size in tests for two means. In: Zar JH, editor. Biostatistical analysis. Upper Saddle River, NJ: Prentice-Hall International, 1999b:132-5.

Zelenka PS, G ao CY, Rampalli A, Arora J, Chauthaiwale V, He HY. Cell cycle regulation in the lens - proliferation, quiescence, apoptosis and differentiation [Review]. Progress in Retinal and E ye Research. 1997;16:303-22.

Zerefos CS, Meleti C, Bais AF, Lambros A. The recent UVB variability over southeastern Europe. J Photochem Photobiol B. 1995;31:159.

Zigman S, D atiles M, Torczynski E. Sunlight and human cataracts. Invest 0 phthalmol V is Sad. 1979;18:462-7.

Zigman S, Paxhia T, McD aniel T, Lou MF, Y u NT. Effect of chronic near-ultraviolet radiation on the gray squirrel lens in vivo. Invest O phthalmol V is Sa. 1991;32:1723-32. 